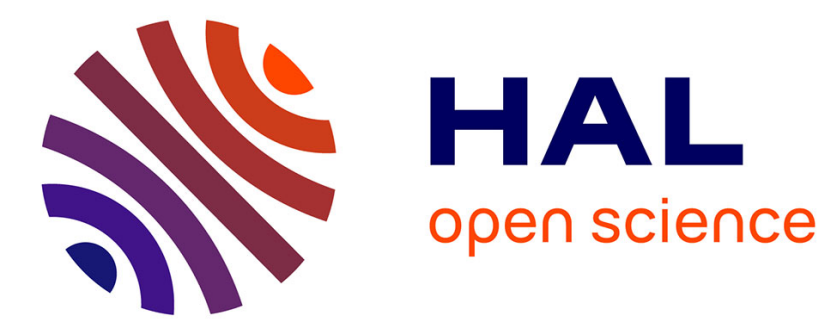

\title{
Self-Confidence and Teamwork: An Experimental Test
} Jean-Louis Rullière, Luis Santos Pinto, Isabelle Vialle

\section{To cite this version:}

Jean-Louis Rullière, Luis Santos Pinto, Isabelle Vialle. Self-Confidence and Teamwork: An Experimental Test. 2011. halshs-00632091

\section{HAL Id: halshs-00632091 https://shs.hal.science/halshs-00632091}

Submitted on 13 Oct 2011

HAL is a multi-disciplinary open access archive for the deposit and dissemination of scientific research documents, whether they are published or not. The documents may come from teaching and research institutions in France or abroad, or from public or private research centers.
L'archive ouverte pluridisciplinaire HAL, est destinée au dépôt et à la diffusion de documents scientifiques de niveau recherche, publiés ou non, émanant des établissements d'enseignement et de recherche français ou étrangers, des laboratoires publics ou privés. 


\section{Self-Confidence and Teamwork} An Experimental Test

Isabelle Vialle, Luis Santos-Pinto, Jean-Louis Rullière

Octobre 2011 


\section{GATE Groupe d'Analyse et de Théorie Économique Lyon-St Étienne}

93, chemin des Mouilles 69130 Ecully - France

Tel. +33 (0)4 72866060

Fax $+33(0) 472866090$

6, rue Basse des Rives 42023 Saint-Etienne cedex 02 - France

Tel. +33 (0)4 77421960

Fax. $+33(0) 477421950$

Messagerie électronique / Email : gate@gate.cnrs.fr

Téléchargement / Download : http://www.gate.cnrs.fr - Publications / Working Papers 


\title{
Self-Confidence and Teamwork: An Experimental Test
}

\author{
Isabelle Vialle $^{a, \dagger}$, Luís Santos-Pinto ${ }^{b}$, Jean-Louis Rullière ${ }^{c}$
}

This version: September 30, 2011

\begin{abstract}
We use a laboratory experiment to study how perceptions of skill influence teamwork. Our design is based on Gervais and Goldstein (2007) theory of teams. Team output is increasing in skill and in effort, skill and effort are complements, and workers' effort choices are complements. An overconfident agent thinks that his skill is higher than it actually is. We find that the presence of overconfident workers in teams is beneficial for firms since it raises effort provision and team output. We also find that overconfidence leads to a Pareto improvement in workers' payoffs. In contrast, underconfidence is detrimental to firms as well as workers.
\end{abstract}

JEL Codes: D81; C91.

Keywords: Teamwork; Self-Confidence; Laboratory Experiment.

${ }^{\dagger}$ Corresponding author. Isabelle Vialle. Present address: THEMA - Université de Cergy-Pontoise - Site des Chênes, 33 boulevard du port, F-95011 CergyPontoise Cedex, France. Ph: 33-134252254. Fax: 33-134256233. E-mail address: Isabelle.Vialle@u-cergy.fr.

${ }^{a, c}$ Université de Lyon, Lyon, F-69007, France ; Université Lyon 2, Lyon, F-69007, France ; CNRS, GATE Lyon St Etienne, Ecully, F-69130, France.

${ }^{b}$ Faculty of Business and Economics, University of Lausanne, Internef 535, CH1015, Lausanne, Switzerland.

E-mail addresses: LuisPedro.SantosPinto@unil.ch, rulliere@gate.cnrs.fr 


\section{Introduction}

Teamwork has increased dramatically in many firms. Gordon (1992) reports that $82 \%$ of companies with 100 or more employees declared they used teamwork and $68 \%$ of Fortune 1000 firms reported that they used self-managing work teams in 1993 compared to 28\% in 1987 (Lawler, Mohrman, and Ledford (1995)). ${ }^{1}$ Lazear and Shaw (2007) observe that from 1987 to 1996 the share of large firms having more than $20 \%$ of employees organized in problemsolving teams rose from $37 \%$ to $66 \%$ and that the percent of large firms with workers in self-managed work teams rose from $27 \%$ to $78 \%$.

One reason firms use teams is that team production can be more productive than individuals working alone. This happens when there are complementarities between the inputs (skills or efforts) of different workers. However, the realization of the potential of these synergistic benefits is not automatic. The classic team model developed by Holmström (1982) shows that workers have an incentive to free-ride on the efforts of other team members when effort choices are unobservable and team output is shared among team members. Consequently, teamwork produces a social dilemma in which individually rational decisions lead to inefficient social outcomes.

The experimental literature on public good provision and teamwork shows that subjects in experiments do not systematically free-ride and that individual characteristics of team members-preferences, beliefs, and demographicslead to heterogeneity in team production (see Ivanova-Stenzel and Kübler (2005), Knez and Simester (2001), Lavy (2002) and Nalbantian and Schotter (1997)). These results gave rise to various models based either on social preferences or on norm enforcement through coercive devices or on specific structures of the team production game.

Some people might not free-ride because they are not purely self-interested but are also led by behavioral motivations like fairness or equity concerns: they view free-riding as an unfair act that violates cooperative social norms (Fehr and Fischbacher (2004) and Fehr and Gächter (2000)). Altruist or conditional cooperation can also lead people to provide higher effort levels than the individually optimal ones (Fischbacher, Gächter, and Fehr (2001) and Sherstyuk et al. (2002)).

\footnotetext{
${ }^{1}$ These and other examples are reported in Cohen and Bailey (1997). Similarly, in examining data of 56,000 U.S. production workers, Capelli and Rogovsky (1994) found that one of the most common skills required by new work practices is the ability to work in a team.
} 
Kandel and Lazear (1992) suggest that peer pressure is a possible solution to the free-riding problem in teams. If team members are able to monitor one another and punish or ostracize those who fail to act cooperatively at a sufficiently low cost, then more cooperative outcomes can be attained. It could also be that people prefer not to free ride because of social approval rather than fear of punishment (Falk and Ichino (2006)).

In a laboratory experiment Bornstein, Erev, and Galili (1993), Bornstein, Erev, and Rozen (1990) and Gunnthorsdottir and Rapoport (2006) compared the performance of two teams in a social dilemma situation facing an intergroup competition. They found that teams competition significantly increased the individual contributions of the teammates.

In this paper, we study experimentally the impact of individuals' beliefs about their skills on effort provision, team production, and payoffs. Individuals might abstain from free-riding in teams if they hold overly positive perceptions of skill. If team output depends positively on skill and effort, skill and effort are complements, and workers' effort choices are complements, then effort provision is higher if workers believe that they are more productive than they actually are.

Research in psychology shows that most people tend to overestimate their skills. For instance, people overestimate their driving ability (Svenson (1981)), their managerial skills (Larwood and Whittaker (1977)), and employees overestimate their job performance (Baker, Jensen, and Murphy (1988) and Myers (1996)).

Laboratory and field studies like Burks et al. (2010), Clark and Friesen (2009), Camerer and Lovallo (1999), Grieco and Hogarth (2009), Hoelzl and Rustichini (2005), Malmendier and Tate (2005), Moore and Cain (2007) and Park and Santos-Pinto (2010) provide evidence that self-perceptions influence behavior in economically relevant situations.

This judgment bias, called overconfidence in self-assessments of skill, has been shown to have both costs and benefits. Smith (1976) suggests that overconfidence explains gambling behavior and the decision to become a soldier. Overconfidence is associated with excess market entry (Camerer and Lovallo (1999)) and value-destroying mergers by CEOs (Malmendier and Tate (2005)). In contrast, overconfidence can be beneficial if it improves motivation leading people to undertake more challenging projects and reach higher performance levels (Bénabou and Tirole (2002), Compte and Postlewaite (2004), Taylor and Brown (1988) and Weinberg (2009)).

The impact of overconfidence on the employment relationship has been 
an active area of research. Hvide (2002) shows that a worker gains from overestimating his skill if that improves his bargaining power against the firm. Bénabou and Tirole (2003) show that if a firm is better informed about a worker's skill than the worker, if effort and self-confidence are complements, then the firm has an incentive to boost the worker's self-perception by offering low-powered incentives that signal trust to the worker and increase motivation. Gervais and Goldstein (2007) show theoretically that overconfidence can reduce free-riding in teams. This result is driven by two effects: the direct effect of overconfidence on own effort provision, and the strategic effect of overconfidence of the team partner on a player's effort provision. They also show that if a team is composed of an unbiased and an overconfident worker, then overconfidence raises the payoff of the unbiased worker and has an ambiguous effect on the payoff of the overconfident worker. Hence, overconfidence can lead to a Pareto improvement of workers' payoffs. ${ }^{2}$

This paper studies the impact of self-confidence on teamwork using a laboratory experiment. We try to find answers to the following questions. To what extent can overconfidence stimulate effort provision and reduce freeriding in teams? Can overconfidence lead to a Pareto improvement of team outcomes? Is there a strategic effect of overconfidence of the team partner on a player's effort provision?

The experiment consists of three parts. In the first part, subjects perform a skill task which consists in solving as many addition problems as they can in five minutes. The second part starts first with a random matching procedure in which the subject with the highest score in a matched pair is assigned high-skill whereas the other subject is assigned low-skill. We then elicit subjects' beliefs about their own skill providing monetary incentives for telling the truth. Comparing subjects' beliefs with their actual skills, we classify them into four groups: unbiased high-skill participants, unbiased low-skill, underconfident, and overconfident. In the third and last part of the experiment, subjects play the team game where they make simultaneous effort choices. Each subject plays the team game once against 14 out of the 19 participants in the room. Before effort decisions are made, we remind subjects of their beliefs about own skill and let them know the belief of skill of each of the 14 team partners. This opens up the possibility that the perception of skill of the team partner influences a subject's effort choice.

\footnotetext{
${ }^{2}$ See also Andolfatto, Mongrain, and Myers (2009), Compte and Postlewaite (2004), Fang and Moscarini (2005), Köszegi (2006), Santos-Pinto (2010) and Santos-Pinto (2008).
} 
Our key results are as follows. All else equal, an overconfident participant provides more effort than an unbiased low-skill participant. A participant provides more effort when the team partner is overconfident than when the team partner is unbiased low-skill. We find that overconfidence improves team output. The output of low-skill teams with overconfident players is higher than the output of low-skill teams with unbiased players. The output of mixed-skill teams with one overconfident and one unbiased player is higher than the output of mixed-skill teams with two unbiased players. Overconfidence leads to a Pareto improvement of players' payoffs since an overconfident participant does not benefit or suffer from his bias and a participant's payoff is higher when his team partner is overconfident rather than unbiased low-skill. We find the opposite effects for underconfidence. Underconfidence lowers effort provision, reduces team output and leads to a Pareto worsening of players' payoffs.

\section{Theoretical Framework}

The seminal contribution to the literature on teamwork and overconfidence is Gervais and Goldstein (2007). They consider a model of teamwork where team output is increasing in workers' skills and effort choices. In this framework, they hypothesize two kinds of complementarities: between effort and ability for each worker, that is, the returns to higher effort of a high-skill agent are greater than those of a low-skill agent; teammates' efforts are complements in production, that is, the returns to higher effort of an agent are higher the greater the effort put in by the team partner.

Gervais and Goldstein (2007) consider a team composed by an overconfident and an unbiased agent. The unbiased agent knows that the overconfident agent is biased, the overconfident agent is unaware of his own bias, knows that the unbiased agent thinks he is biased but disagrees with the unbiased agent.

The first main finding in Gervais and Goldstein (2007) is that overconfidence reduces underprovision of effort in teams. The intuition behind this result is as follows. Since effort and skill are complements in production, overconfidence makes higher effort more attractive to an overconfident agent. Hence, there is a positive direct effect of overconfidence on the effort choice of the overconfident agent. Additionally, since agents' efforts are complements in production, the higher effort of the overconfident agent makes higher ef- 
fort more valuable to the unbiased agent. In other words, the unbiased agent works harder because he knows that the potential synergistic gains from higher effort are higher with an overconfident team partner. Hence, there is a positive strategic effect of overconfidence on the effort choice of the unbiased agent.

The second main result in Gervais and Goldstein (2007) is that overconfidence can give rise to a Pareto improvement in the sense that not only the team and the unbiased agent are better off but also the overconfident agent can be better off than if he had been unbiased. An overconfident worker's payoff decreases as he bears a cost due to his extra effort (direct effect of overconfidence), but at the same time it increases as his partner also provides more effort (strategic effect of overconfidence). In contrast, underconfidence leads to a Pareto worsening since it reduces team output and the payoffs of the unbiased and the underconfident teammates.

In Gervais and Goldstein (2007)'s team game there is complete information since each agent places a probability equal to one on a particular skill level. This assumption is not realistic for a laboratory experiment since individuals are likely to have non-degenerate beliefs about their own skills. Hence, in order to take their theoretical framework to an experimental protocol, we extend Gervais and Goldstein (2007)'s model by assuming that agent $i$ places probability $q_{i} \in[0,1]$ on having high-skill, that is, agents have incomplete information about their own skills. We now show that their results also apply in this set-up. ${ }^{3}$

Let team output be given by

$$
Q\left(e_{1}, e_{2}\right)=2 w\left(a_{1} e_{1}+a_{2} e_{2}+s e_{1} e_{2}\right)
$$

where $e_{i}$ is the level of effort of player $i, a_{i}$ is a random variable which represents agent $i$ 's skill and can take on two values $\left\{a_{L}, a_{H}\right\}$ with $0<a_{L}<$ $a_{H}, w>0$ and $s>0$. Agents are risk neutral and have cost of effort $c\left(e_{i}\right)=c e_{i}^{2}$, where $c>0$.

The ex-post payoff of agent $i$ is the difference between half of the team output and cost of effort of agent $i$ :

$$
U_{i}=w\left(a_{i} e_{i}+a_{j} e_{j}+s e_{i} e_{j}\right)-c e_{i}^{2} .
$$

Denote the expected ability of agent $i$ by $E\left(a_{i}\right)=\bar{a}_{i}=\left(1-p_{i}\right) a_{L}+p_{i} a_{H}$, where $p_{i} \in[0,1]$ is the probability agent $i$ has high ability, that is, $p_{i}=\operatorname{Pr}\left(a_{i}=a_{H}\right)$.

\footnotetext{
${ }^{3}$ Gervais and Goldstein (2007)'s results are available in Appendix A.
} 
Agent $i$ chooses effort to maximize his ex-ante expected payoff

$$
E_{p}\left(U_{i}\right)=w\left(\bar{a}_{i} e_{i}+\bar{a}_{j} e_{j}+s e_{i} e_{j}\right)-c e_{i}^{2} .
$$

The solution to this problem is $e_{i}=\frac{w}{2 c}\left(\bar{a}_{i}+s e_{j}\right)$. The solution concept for this static game of incomplete information is Bayesian Nash equilibrium (BNE from now on). The BNE effort level of agent $i$ is

$$
e_{i}=2 \frac{c w}{d} \bar{a}_{i}+\frac{s w^{2}}{d} \bar{a}_{j} .
$$

where $d=4 c^{2}-s^{2} w^{2}>0$ or $s<2 c / w$.

To introduce self-confidence we assume that the perceived expected ability of agent $i$ is $E\left(A_{i}\right)=\bar{A}_{i}=\left(1-q_{i}\right) a_{L}+q_{i} a_{H}$ where $q_{i} \in[0,1]$ is agent $i$ 's belief that he has high ability, that is, $q_{i}=\operatorname{Pr}\left(A_{i}=a_{H}\right)$. Hence, agent $i$ 's self-perception bias is $\bar{b}_{i}=\bar{A}_{i}-\bar{a}_{i}=\left(q_{i}-p_{i}\right)\left(a_{H}-a_{L}\right) \in\left[-a_{H}+a_{L}, a_{H}-a_{L}\right]$. Agent $i$ chooses effort to maximize his perceived ex-ante expected payoff

$$
E_{q}\left(U_{i}\right)=w\left[\bar{A}_{i} e_{i}+\bar{a}_{j} e_{j}+s e_{1} e_{2}\right]-c e_{i}^{2} .
$$

The solution to this problem is $e_{i}=\frac{w}{2 c}\left(\bar{A}_{i}+s e_{j}\right)$. The BNE effort of agent $i$ as a function of agents' perceived expected abilities is given by

$$
e_{i}=2 \frac{c w}{d} \bar{A}_{i}+\frac{s w^{2}}{d} \bar{A}_{j} .
$$

The hypothesis that we will test first is whether effort choices are consistent with perceived expected abilities.

Hypothesis 0: Players' effort choices are consistent with their beliefs.

The BNE effort of agent $i$ as a function of agents' expected abilities and self-perception biases is obtained from (2) by replacing $\bar{A}_{i}$ and $\bar{A}_{j}$ by $\bar{a}_{i}+\bar{b}_{i}$ and $\bar{a}_{j}+\bar{b}_{j}$, respectively:

$$
e_{i}=2 \frac{c w}{d} \bar{a}_{i}+\frac{s w^{2}}{d} \bar{a}_{j}+2 \frac{c w}{d} \bar{b}_{i}+\frac{s w^{2}}{d} \bar{b}_{j} .
$$

From (3) we can derive hypotheses 1, 2 and 3.

Hypothesis 1: (a) There is a positive direct effect of the skill of player $i$ on his own effort; (b) There is a positive strategic effect of the skill of player $j$ on the effort of player $i$. 
When agent $i$ is overconfident, $\bar{b}_{i}>0$, an increase in overconfidence of agent $i$ raises the effort of agent $i$. In contrast, when agent $i$ is underconfident, $\bar{b}_{i}<0$, an increase in underconfidence of agent $i$ reduces the effort of agent $i$.

Hypothesis 2: (a) There is a positive direct effect of overconfidence of player $i$ on his own effort; (b) There is a negative direct effect of underconfidence of player $i$ on his own effort.

When agent $j$ is overconfident, $\bar{b}_{j}>0$, an increase in overconfidence of agent $j$ raises the effort of agent $i$. In contrast, when agent $j$ is underconfident, $\bar{b}_{j}<0$, an increase in underconfidence of agent $j$ reduces the effort of agent $i$.

Hypothesis 3: (a) There is a positive strategic effect of overconfidence of player $j$ on the effort of player $i$; (b) There is a negative strategic effect of underconfidence of player $j$ on the effort of player $i$.

Our next results concern the impact of biased beliefs on team output. Using the equilibrium effort levels $e_{1}$ and $e_{2}$ determined by (3), the ex-post team output is

$$
Q\left(\bar{b}_{1}, \bar{b}_{2}\right)=2 w\left[a_{1} e_{1}\left(\bar{b}_{1}, \bar{b}_{2}\right)+a_{2} e_{2}\left(\bar{b}_{1}, \bar{b}_{2}\right)+s e_{1}\left(\bar{b}_{1}, \bar{b}_{2}\right) e_{2}\left(\bar{b}_{1}, \bar{b}_{2}\right)\right] .
$$

Differentiating (4) with respect to $\bar{b}_{1}$ and $\bar{b}_{2}$ we obtain:

$$
\begin{aligned}
\frac{\partial Q}{\partial \bar{b}_{1}} d \bar{b}_{1}+\frac{\partial Q}{\partial \bar{b}_{2}} d \bar{b}_{2} & =2 w\left[\left(a_{1}+s e_{2}\right) \frac{\partial e_{1}}{\partial \bar{b}_{1}}+\left(a_{2}+s e_{1}\right) \frac{\partial e_{2}}{\partial \bar{b}_{1}}\right] d \bar{b}_{1} \\
& +2 w\left[\left(a_{1}+s e_{1}\right) \frac{\partial e_{1}}{\partial \bar{b}_{2}}+\left(a_{2}+s e_{2}\right) \frac{\partial e_{2}}{\partial \bar{b}_{2}}\right] d \bar{b}_{2} .
\end{aligned}
$$

From (3) we have if $\bar{b}_{i}>0$ and $\bar{b}_{j}>0$, then $\frac{\partial e_{i}}{\partial \bar{b}_{i}}>0$ and $\frac{\partial e_{i}}{\partial \bar{b}_{j}}>0$. Hence, when both team members are overconfident, an increase in overconfidence increases team output. Obviously, the reverse happens when both team members are underconfident.

Hypothesis 4: (a) Team output is increasing with an increase in overconfidence of the team members; (b) Team output is decreasing with a increase in underconfidence of the team members.

Finally, our next results concern the impact of biased beliefs on players' ex-post payoffs (the results are derived in Appendix B). Regarding the impact of biased beliefs on the ex-post payoffs of unbiased agents, we have the following results. 
Hypothesis 5: (a) The ex-post payoff of an unbiased agent is increasing with an increase in overconfidence of the team partner; (b) The ex-post payoff of an unbiased agent is decreasing with an increase in underconfidence of the team partner.

Furthermore, regarding the impact of biased beliefs on the ex-post payoffs of biased agents, we have the following results.

Hypothesis 6: (a) The ex-post payoff of an overconfident agent, in a team with an unbiased agent, is increasing in overconfidence if and only if overconfidence is sufficiently small; (b) The ex-post payoff of an underconfident agent, in a team with an unbiased agent, is decreasing in underconfidence.

\section{Design of the Experiment}

Our experiment consists of two main treatments called "Belief" and "Type and Belief" and each treatment is divided into three successive parts. For each treatment, our behavioral predictions are based on the analysis of the Bayesian Nash Equilibrium, as it is characterized in the Section 2. We set $w=3, s=5 / 12$, and $c=1.5$. Low-skill subjects have a marginal productivity of $3\left(a_{L}=3\right)$ and high-skill subjects of $7\left(a_{H}=7\right)$.

The experimental sessions were conducted at the University of Lyon (GATE). They were run in a computerized way using Regate-NG as experimental software. 120 subjects were recruited from the undergraduate population at the Management School of Lyon and an engineering school, École Centrale de Lyon. Three sessions, each involving 20 participants, were conducted for each of two treatments. Each subject participated in a single session. Details on the experimental design are provided in Appendix C.

Upon arrival at the laboratory, subjects are randomly assigned to a computer. The written instructions are then distributed and read aloud; so that it is common information that everybody is involved in the same experiment. At the end, subjects are privately paid their earnings, calculated according to the conversion rate 35 points are equal to 1 Euro. A show-up fee of 2 Euros is added. Each session lasted around 75 minutes and mean earnings are approximately 17 Euros.

From the beginning, subjects are explicitly told that the experiment is divided into three parts. The instructions corresponding to each part are distributed and read just before the part starts. This procedure prevents 
us from behavior in one part being affected by the rules of the subsequent one(s) and by some behavioral expectations.

The first part of the experiment consists of a skill task. Subjects have five minutes to solve a series of addition problems. A correct answer gives a subject 2 points and a wrong answer 0 point. Before performing the task, subjects are allowed to practice it during one minute and are informed that the number of correct answers and the speed at which they complete the task will, amongst other factors, determine how easy it is for them to obtain some points later in the experiment. This increases the incentives to perform well in the skill task without increasing the cost of the experiment. Subjects are told neither their score on the skill task nor the earnings until the end of the experimental session.

The second part of the experiment starts with a matching protocol: a computer program randomly matches subjects into pairs and compares the scores of subjects in each pair (from the first part). The subject who got the highest score in each pair is assigned to a high type and the other one to a low type. If both subjects in a pair have the same score, the answer time breaks the tie (the fastest participant is assigned the high type). After this matching, subjects' beliefs about their own type are elicited: each subject is asked to report the type he believes he is. Each subject is paid 5 Euros for making an accurate forecast and 0 Euro otherwise. The monetary payment for making a correct guess implies that if a subject thinks that he has more than $50 \%$ probability of being a high type, then his self-assessment should be of high type. Note that at this stage subjects do not know that their beliefs about skill will play a critical role in the team game since the instructions to the third part of the experiment are only distributed after the second part is over.

The third part of the experiment consists of the team game. This part of the experiment involves two information treatments. In treatment "Belief," each subject is told privately the stated belief of each team partner. In treatment "Type and Belief," each subject is told privately the stated belief and the type of each team partner. In other words, in treatment "Belief" subjects only know the partner's self-evaluation whereas in treatment "Type and Belief" they know both the partner's type and self-evaluation. From the theoretical point of view, these two treatments are equivalent because each individual's equilibrium effort decision is based only on his own and the team partner's beliefs.

We use a stranger matching design where each subject plays the team 
game once against 14 out of the 19 other participants in the room. ${ }^{4}$ In each of the 14 games, subjects choose an effort level simultaneously and independently among four possible values 6, 8, 10 or 12 . Subjects do not receive any feedback from one decision to another to rule out learning effects. Last, subjects are told that only one decision out of the 14 will determine earnings regarding effort choices. That decision is randomly drawn at the end of the experiment. This rules out wealth and portfolio effects.

In order to make their decisions, subjects are given a sheet of paper with four payoff matrices, one for each of the four possible types of pairs of player combinations. Each payoff matrix displays the players' payoffs for the 16 possible pairs of effort combinations. ${ }^{5}$ In order to improve subjects' understanding of the team game, subjects are requested to complete some exercises with the payoff matrices. The experimentalist checked the answers and reexplained the game in private in case a subject's answers indicated lack of understanding of the game. Instructions are kept as neutral as possible as regards to a teamwork context. The high- and low-type subjects are presented as "Type A" and "Type B" participants. The words "coefficient" and "number" are used instead of "marginal productivity of effort" and "effort choice".

After completing the third part of the experiment, subjects are told their type, the type of the partner, the effort choices, and the earnings for the randomly drawn effort decision. They are also told their earnings in the skill task and self-assessment of skill. The participants are then asked to answer a questionnaire providing their individual characteristics (gender, age, etc.). Subjects in our sample are briefly described in Table 1.

insert Table 1 here

\section{Findings}

In this section we present the main findings of the experiment.

\footnotetext{
${ }^{4}$ The algorithm that determines team compositions ensures that each subject plays against 7 high-skill partners and 7 low-skill partners. This information was not provided to the subjects.

${ }^{5}$ See the end of instructions in Appendix C.
} 


\subsection{Self-Confidence}

To describe self-confidence in our sample we divide subjects into four groups according to their actual skills (low or high) and their beliefs about skill (biased or unbiased).

A subject who makes a correct self-evaluation of skill is called unbiased whereas a subject who makes an incorrect self-evaluation of skill is called biased. A low-skill subject who states he has high-skill is called overconfident and a high-skill subject who states he has low-skill is called underconfident. We take no stand here whether the observed biases (overconfidence and underconfidence) are rational or irrational. For a discussion of rational and irrational self-confidence biases see Benoit and Dubra (2011).

Table 2 displays the number and the proportion of players in each group for the full sample, treatment "Belief" and treatment "Type and Belief".

insert Table 2 here

Table 2 shows that approximately $55 \%$ of subjects are unbiased whereas $45 \%$ display self-confidence biases. Additionally, we see that overconfidence is more frequent in our sample than underconfidence: $27 \%$ of players are overconfident and only $18 \%$ are underconfident. A test of proportions shows there are significantly more overconfident subjects among low-skill players than underconfident subjects among high-skill players $(p=0.066)$. Distinguishing the treatments "Belief" and "Type and Belief", we observe almost the same distributions. A Kolmogorov-Smirnov test for the equality of the distributions confirms that the proportion of subjects in each of the four groups does not differ significantly from one treatment to another $(p=1.000)$.

\subsection{Play of BNE}

For the chosen team game parameterization, we can compute the BNE effort choices for all possible combinations of beliefs $\left(q_{1}, q_{2}\right) \in[0,1] \times[0,1]$. However, we don't observe the exact $q_{i}$ of each subject since we just ask subjects if they think they are high or low type. Additionally, effort choices are constrained to belong to the set $\{6,8,10,12\}$. Taking this into consideration, Table 3 displays the set of BNE effort levels consistent with players' beliefs about skill, $\Gamma\left(q_{1}, q_{2}\right)$.

insert Table 3 here 
A team plays a BNE when the players' effort choices belong to the set of equilibrium effort levels consistent with players' beliefs, $\Gamma\left(q_{1}, q_{2}\right)$. The percentage of teams that play a BNE as a function of team composition in terms of players' skills and beliefs is displayed in Table 4.

insert Table 4 here

We can see from Table 4 that approximately half of the teams in our sample plays a BNE. This result is consistent with experimental evidence which shows that in strategic settings without clear precedents, individuals' initial responses often deviate systematically from equilibrium and that there is substantial heterogeneity in strategic sophistication. ${ }^{6}$

Table 4 also shows that compliance with equilibrium varies with team composition. High-skill teams (two high-skill players) play an equilibrium in $60 \%$ of cases, mixed-skill teams (a low- and a high-skill player) play an equilibrium in $51 \%$ of cases, and low-skill teams (two low-skill players) play an equilibrium in $44 \%$ of cases. A test of proportions shows that high-skill teams have a higher compliance rate with equilibrium than low-skill teams $(p=0.001)$ and mixed-skill teams $(p=0.036)$ but the compliance rates of low- and mixed-skill teams are not significantly different $(p=0.102)$.

Unbiased teams play an equilibrium in $62 \%$ of cases. In contrast, biased teams (those where at least one player has biased beliefs) do it only in $47 \%$ of cases ( $62 \%$ is different from $47 \%$ at $1 \%$ significance level). Teams where both players are underconfident play an equilibrium in $55 \%$ of cases but teams where both players are overconfident only do it in $37.5 \%$ of cases. Teams where one player is unbiased and the other overconfident play an equilibrium in $52 \%$ of cases, and those where one player is unbiased and the other underconfident do it in $41 \%$ of cases.

Result 0: 52\% of teams play effort levels which are consistent with players' beliefs about skill. The compliance rate with BNE varies with team composition: it is increasing with players' skills, but decreasing with players' self-confidence biases.

\subsection{Effort Choices}

In the experiment, each player makes 14 effort decisions that are constrained to belong to the set $\{6,8,10,12\}$. The information provided to the play-

\footnotetext{
${ }^{6}$ See Camerer, Ho, and Chong (2004), Costa-Gomes, Crawford, and Broseta (2001), Nagel (1995) and Stahl and Wilson (1995).
} 
ers about their partners' actual skill differs from one treatment to another, but the players always know their partners' beliefs. Taking this into consideration, Table 5 displays the distribution of effort choices as a function of players' skill and belief, and partners' belief.

insert Table 5 here

Table 5 shows that, conditional on the partner's belief, the distribution of effort choices of overconfident players first-order stochastically dominates that of unbiased low-skill players. In contrast, the distribution of effort choices of underconfident players is first-order stochastically dominated by that of unbiased high-skill players. Kolmogorov-Smirnov tests for the equality of the distributions confirm that the distributions of effort choices differ significantly between overconfident and unbiased low-skill players, whatever partner's belief is $(p<0.0001)$. We also find significant differences when we compare the effort distributions of unbiased and underconfident high-skill players $(p<0.0001)$.

Table 5 also shows that, conditional on a player's skill and belief, players choose higher effort levels when their team partners have a high belief of skill than when the team partners have a low belief.

The effort choice of a subject who plays an equilibrium is determined by his own perception of skill and that of his team partner, $A_{i}$ and $A_{j}$, respectively, according to (2). Therefore, to show that beliefs about skill have an impact on effort we estimate the ordered probit model:

$$
e_{i j}^{*}=\alpha_{1} A_{i}+\alpha_{2} A_{j}+\alpha_{z} z_{i}+\varepsilon_{i j},
$$

where $e_{i j}^{*}$ is a latent continuous variable that represents the effort of player $i$ when player $j$ is the team partner, $e_{i j}$, the observed ordinal variable, takes on values $6,8,10$ or $12, i=1, \ldots, 120$, and, for each $i$ there are 14 different team partners $j$. The variable $A_{i}$ takes the value of 1 when player $i$ believes to have high-skill and 0 otherwise, and $A_{j}$ takes the value of 1 when player $j$ believes to have high-skill and 0 otherwise. The variable $z_{i}$ is a vector of control variables of player $i$ that includes gender, age, marital status, student status, years of education, field of study, children, years of education of father, years of education of mother, and previous participation in experiments. Finally, we cluster standard errors at the subject level.

When subjects make their effort choices they do not know their actual skill, $a_{i}$ and, in treatment "Belief," they also don't know the actual skill of the team partner, $a_{j}$. However, at the end of the experiment we know 
subjects' actual skills, $a_{i}$ and $a_{j}$, and self-perception biases, $b_{i}$ and $b_{j}$, and we can use that information to decompose the impact of perceptions of skill on effort using (3). Thus, to show that self-confidence biases have an impact on effort we estimate the ordered probit model:

$$
e_{i j}^{*}=\beta_{1} a_{i}+\beta_{2} a_{j}+\beta_{3} b_{1 i}+\beta_{4} b_{2 i}+\beta_{5} b_{1 j}+\beta_{6} b_{2 j}+\beta_{z} z_{i}+\varepsilon_{i j} \text {, }
$$

where $a_{i}$ takes the value of 1 when player $i$ has high-skill and 0 otherwise, and $a_{j}$ takes the value of 1 when player $j$ has high-skill and 0 otherwise. The variables $b_{1 i}, b_{2 i}, b_{1 j}$, and $b_{2 j}$ capture self-confidence of players $i$ and $j$. The variable $b_{1 i}$ takes the value of 1 when player $i$ is overconfident and 0 otherwise, and $b_{2 i}$ takes the value of 1 if player $i$ is underconfident and 0 otherwise. The omitted category, to which $b_{1 i}$ and $b_{2 i}$ are compared, refers to the case when player $i$ has a correct assessment of skill. The variable $b_{1 j}$ takes the value of 1 when player $j$ is overconfident and 0 otherwise, and $b_{2 j}$ takes the value of 1 if player $j$ is underconfident and 0 otherwise. The omitted category, to which $b_{1 j}$ and $b_{2 j}$ are compared, refers to the case when player $j$ has a correct assessment of skill. ${ }^{7}$

Table 6 reports the results from estimating equations (5) and (6).

insert Table 6 here

We see from Table 6 that the estimates for $\alpha_{1}$ and $\alpha_{2}$ are both positive and significant, that is, a player's effort is increasing with own belief about skill and with the team partner's belief. The estimate for $\alpha_{1}$ is significantly greater than that for $\alpha_{2}$. This is consistent with (2) and the assumption $s<2 c / w$ which imply that the impact of a player's belief about skill on own effort is greater than the impact of the team partner's belief.

We also see from Table 6 that we find support for a positive direct effect of the skill of a player on effort (hypothesis 1a). The estimate for $\beta_{1}$ is positive and significant which indicates that, on average, a high-skill player provides more effort than a low-skill player. We also find support for a positive strategic effect of the skill of the team partner on own effort (hypothesis 1b). The estimate for $\beta_{2}$ is positive and significant which indicates that, on

\footnotetext{
${ }^{7}$ This specification implies that $a_{i}$ and $b_{1 i}$ are negatively correlated (a high-skill player cannot be overconfident) and that $a_{i}$ and $b_{2 i}$ are positively correlated (a low-skill player cannot be underconfident). Similarly, $a_{j}$ and $b_{1 j}$ are negatively correlated and $a_{j}$ and $b_{2 j}$ are positively correlated. These correlations do not bias the estimates but generate large standard errors. The large standard errors make it harder to find statistically significant effects of self-confidence biases on effort.
} 
average, a player provides more effort when the team partner has high-skill than when the team partner has low-skill.

Result 1: (a) All else equal, a high-skill player provides more effort than a low-skill player; (b) All else equal, a player provides more effort when the team partner has high-skill than when the team partner has low-skill.

We find support for a positive direct effect of own overconfidence on effort (hypothesis $2 \mathrm{a}$ ). On average, overconfident players provide more effort than unbiased low-skill players since the estimate for $\beta_{3}$ is positive and significant. We also find support for a negative direct effect of own underconfidence on effort (hypothesis $2 \mathrm{~b}$ ). On average, underconfident players provide less effort than unbiased high-skill players since the estimate for $\beta_{4}$ is negative and significant.

Result 2: (a) All else equal, overconfident players provide more effort than unbiased low-skill players; (b) All else equal, underconfident players provide less effort than unbiased high-skill players.

Finally, we find support for a positive strategic effect of overconfidence of the team partner on own effort (hypothesis 3a). The estimate for $\beta_{5}$ is positive and significant which indicates that, on average, a player provides more effort when the team partner is overconfident than when the team partner is unbiased low-skill. We also find support for a negative strategic effect of underconfidence of the team partner on own effort (hypothesis 3b). The estimate for $\beta_{6}$ is negative and significant which indicates that, on average, a player provides less effort when the team partner is underconfident than when the team partner is unbiased high-skill.

Result 3: (a) All else equal, a player provides more effort when the team partner is overconfident than when the team partner is unbiased low-skill; (b) All else equal, a player provides less effort when the team partner is underconfident than when the team partner is unbiased high-skill.

Including the control variables the effects persist. All effects are significant at $1 \%$, except the strategic effect of overconfidence of the team partner on a player's effort, which is significant at $10 \%$. The only significant control variables are age and gender: all else equal, older subjects put in less effort than younger ones and women put in less effort than men. ${ }^{8}$

\footnotetext{
${ }^{8}$ The absolute values of the estimates for $\beta_{1}, \beta_{3}$ and $\beta_{4}$ are not significantly different from the estimate for $\alpha_{1}$. Additionally, the absolute values of the estimates for $\beta_{2}$
} 


\subsection{Team Output}

To analyze the impact of self-confidence on team output we divide teams into groups according to the skills of the team members: high-skill teams (two high-skill players), mixed-skill teams (one high-skill and one low-skill player), and low-skill teams (two low-skill players). These three types of teams are further divided into subgroups according to players' beliefs about skill leading to a total of 10 different team compositions.

Table 7 displays the mean team output of each team composition.

\section{insert Table 7 here}

The second column in Table 7 shows that the mean team output of lowskill teams increases with the number of overconfident players. The mean team output of a low-skill team with two overconfident players (563) is greater than that of a low-skill team with one unbiased and one overconfident player (538) which, in turn, is greater than the mean team output of a low-skill team with two unbiased players (422).

The fourth column shows that the mean team output of a mixed-skill team with one unbiased and one underconfident player (664) is smaller than the mean team output of a mixed-skill team with two unbiased players (792) which, in turn, is smaller than the mean team output of a mixed-skill team with one unbiased and one overconfident player (890).

Finally, the sixth column shows that the mean team output of high-skill teams decreases with the number of underconfident players. The mean team output of a high-skill team with two underconfident players (882) is smaller than that of a high-skill team with one unbiased and one underconfident player (986) which, in turn, is smaller than the mean team output of a highskill team with two unbiased players (1231).

To show that overconfidence has an impact on the output of low-skill teams we estimate the following equation by ordinary least squares:

$$
Q_{i}^{L}=\beta_{0}^{L}+\beta_{1}^{L} \text { Two_Over }_{i}+\beta_{2}^{L} \text { One_Over }_{i}+\beta_{3}^{L} z_{i}+\varepsilon_{i}
$$

where the dependent variable $Q_{i}^{L}$ denotes the ex-post output of a low-skill team. The variable Two_Over ${ }_{i}$ takes the value 1 if a low-skill team has two

and $\beta_{6}$ are not significantly different from the estimate for $\alpha_{2}$ but the estimate for $\beta_{5}$ is marginally significantly different from the estimate for $\alpha_{2}(p=0.0436)$. These results are consistent with the decomposition of players' beliefs about skill into actual skill and overand underconfidence biases in (3). 
overconfident players and 0 otherwise. The variable One_Over ${ }_{i}$ takes the value 1 if a low-skill team has only one overconfident player and 0 otherwise. The variable $z_{i}$ consists of a vector team demographics including team age (the sum of ages of players), team education (the sum of years of education of players), team mothers' education (the sum of years of education of players' mothers), team fathers' education (the sum of years of education of players' fathers), and dummies for team gender composition, marital status, student status, field of study, children and previous participation in an experiment. ${ }^{9}$

The second and third columns of Table 8 report the estimates for the coefficients in (7) without and with team demographics, respectively.

insert Table 8 here

We start by discussing the results obtained without controls. We find that the output of a low-skill team with two overconfident players is greater than that of a low-skill team with two unbiased players since the estimate for $\beta_{1}^{L}$ is positive and significant. We also find that the output of a low-skill team with only one overconfident player is greater than that of a low-skill team with two unbiased players since the estimate for $\beta_{2}^{L}$ is positive and significant. All effects are significant at $1 \%$.

Including the control variables the effects persist. The only significant control variable (only at 10\%) for low-skill teams is marital status: all else equal, a low-skill team where only one of the players is married produces lower output than a low-skill team where both players are single.

We use a similar approach to show that underconfidence has an impact

\footnotetext{
${ }^{9}$ More precisely, dummies are defined as follows. "Mixed gender" is equal to 1 if the team includes only one female and 0 otherwise, while "Female gender" is equal to 1 if the team includes two females. The reference category for team gender composition is teams with two males. Regarding marital status, "One married player" is 1 if only one of the players is married and 0 otherwise, and "Two married players" is 1 if both players are married and 0 otherwise. The reference category is teams with two single players. "Student" is 1 if both players are student and 0 otherwise. The reference category is teams that include at most one student. "No student in economics" is 1 if none of both players studies economics and management, while "One student in economics" is 1 if only one of the players studies economics and management. The reference category is teams with two students in economics and management. "Child" is 1 if one or both players have at least one child and 0 otherwise. The reference category is teams that include two players without any child. "Participation in experiment" is equal to 1 if both players previously participated in an experiment and 0 otherwise. The reference category is teams that include at least one player who never participated in an experiment.
} 
on the output of high-skill teams:

$$
Q_{i}^{H}=\beta_{0}^{H}+\beta_{1}^{H} \text { Two_Under }_{i}+\beta_{2}^{H} \text { One_Under }_{i}+\beta_{3}^{H} z_{i}+\varepsilon_{i},
$$

where the dependent variable $Q_{i}^{H}$ denotes the ex-post output of a high-skill team, Two_Under ${ }_{i}$ takes the value 1 if a high-skill team has two underconfident players and 0 otherwise, and the variable One_Under $_{i}$ takes the value 1 if a high-skill team has only one underconfident player and 0 otherwise.

The two last columns of Table 8 report the estimates for the coefficients in (8) without and with team demographics, respectively.

We find that the output of a high-skill team with two underconfident players is smaller than that of a high-skill team with two unbiased players since the estimate for $\beta_{1}^{H}$ is negative and significant. We also find that the output of a high-skill team with only one underconfident player is smaller than that of a high-skill team with two unbiased players since the estimate for $\beta_{2}^{H}$ is negative and significant. All effects are significant at $1 \%$.

Including the control variables the effects persist. The only significant control variables for high-skill teams are the sum of years of education of players and the sum of years of education of players' fathers (both at 5\%): all else equal, high-skill teams with more educated players produce higher output and so do high-skill teams whose players have more educated fathers.

To show that self-confidence has an impact on the output of mixed-skill teams we estimate the following equation by ordinary least squares:

$Q_{i}^{M}=\beta_{0}^{M}+\beta_{1}^{M}$ One_Under $_{i}+\beta_{2}^{M}$ One_Over $_{i}+\beta_{3}^{M}$ Two_Biased $_{i}+\beta_{4}^{M} z_{i}+\varepsilon_{i}$,

where the dependent variable $Q_{i}^{M}$ denotes the ex-post output of a mixed-skill team. The variable One_Over $_{i}$ takes the value 1 if a mixed-skill team has one overconfident and one unbiased player. The variable One_Under $_{i}$ takes the value 1 if a mixed-skill team has one underconfident and one unbiased

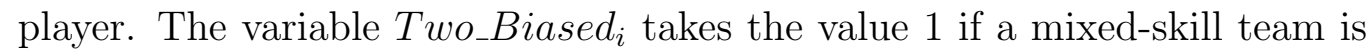
composed by one underconfident and one overconfident player.

The fourth and fifth columns of Table 8 report the estimates for the coefficients in (9) without and with team demographics, respectively.

We find that the output of a mixed-skill team with one underconfident and one unbiased player is smaller than that of a mixed-skill team with two unbiased players since the estimate for $\beta_{1}^{M}$ is negative and significant. We also find that the output of a mixed-skill team with one overconfident and one unbiased player is higher than that of a mixed-skill team with two unbiased 
players since the estimate for $\beta_{2}^{M}$ is positive and significant. Finally, we find that the output of a mixed-skill team with two biased players is lower than that of a mixed-skill team with two unbiased players since the estimate for $\beta_{3}^{M}$ is negative and significant. All effects are significant at $1 \%$.

Including the control variables the effects persist. For mixed-skill teams we find the following significant control variables: team gender composition, team age, and team marital status. All else equal, mixed-skill teams with two females produce lower output than mixed-skill teams with two males (at 1\%). All else equal, mixed-skill teams with only one female produce lower output than mixed-skill teams with two males (at 5\%). All else equal, mixed-skill teams with older players produce less output and mixed skill teams where only one of the players is married produce less output than mixed-skill teams where both players are single (both at $5 \%$ ).

Result 4: (a) The output of low-skill teams increases with overconfidence of the team members; (b) The output of high-skill teams decreases with underconfidence of the team members; (c) The output of mixed-skill teams with one overconfident and one unbiased player is higher than the output of mixed-skill teams with two unbiased players which, in turn, is higher than the output of mixed-skill teams with one underconfident and one unbiased player.

Hence, for any team skill composition (low-skill, mixed-skill and highskill), we find that mean team output increases with the number of overconfident players and decrease with the number of underconfident players. These results support hypotheses $4 \mathrm{a}$ and $4 \mathrm{~b}$.

\subsection{Players' Payoffs}

Let us now turn to the impact of self-confidence on players' payoffs. Table 9 displays the mean payoff of subjects as a function of their own and their partners' skill and belief.

insert Table 9 here

We can see from Table 9 that, comparing a player's payoff when the partner is unbiased to a player's payoff when the partner is overconfident, having an overconfident team partner is beneficial (hypothesis 5a). In contrast, having an underconfident team partner reduces one's payoff (hypothesis 5b).

Table 9 also shows us that the mean payoff of an overconfident player is approximately equal to the mean payoff of an unbiased low-skill player, 
except when the team partner is underconfident. This suggests that the negative direct effect of overconfidence on an overconfident player's payoff more or less compensates the positive strategic effect.

Table 9 also shows us that the mean payoff of an underconfident player is substantially lower than the mean payoff of an unbiased high-skill player, except when the team partner is underconfident. This is consistent with the negative direct and strategic effects of underconfidence on the payoff of an underconfident player (hypothesis 6b).

To show that self-confidence has an impact on players' payoffs we estimate the following equation by ordinary least squares:

$$
U_{i j}=\beta_{0}+\beta_{1} a_{i}+\beta_{2} a_{j}+\beta_{3} b_{1 i}+\beta_{4} b_{2 i}+\beta_{5} b_{1 j}+\beta_{6} b_{2 j}+\beta_{z} z_{i}+\varepsilon_{i j},
$$

where the dependent variable $U_{i j}$ denotes the ex-post payoff of player $i$ when player $j$ is the team partner. The other variables are the same as in (6). Standard errors are clustered at the subject level.

The estimates for the coefficients in (10) are reported in Table 10.

insert Table 10 here

We start by discussing the results obtained without controls. We find that, on average, the payoff of a high-skill player is greater than that of a low-skill player since the estimate for $\beta_{1}$ is positive and significant. We also find that, on average, the payoff of a player is greater when the team partner has high-skill than when the team partner has low-skill since the estimate for $\beta_{2}$ is positive and significant.

We find support for a positive strategic effect of overconfidence of the team partner on own payoff (hypothesis 5a). The estimate for $\beta_{5}$ is positive and significant which indicates that, on average, a player's payoff is greater when the team partner is overconfident than when the team partner is unbiased low-skill. We also find support for a negative strategic effect of underconfidence of the team partner on own payoff (hypothesis 5b). The estimate for $\beta_{6}$ is negative and significant which indicates that, on average, a player's payoff is lower when the team partner is underconfident than when the team partner is unbiased high-skill.

Result 5: (a) All else equal, the ex-post payoff of a player increases with overconfidence of the team partner; (b) All else equal, the ex-post payoff of a player decreases with underconfidence of the team partner.

We find that the estimate for $\beta_{3}$ is not significantly different from zero which indicates that, on average, the payoff of an overconfident player is equal 
to that of an unbiased low-skill player. This result is consistent with hypothesis 6 a even though we cannot distinguish between low and high overconfidence levels. Overconfidence has a negative direct effect on an overconfident player's payoff since it leads to an optimization loss (an overconfident player maximizes the perceived payoff function not the actual one) but a positive strategic effect since it raises the effort of the team partner. If the two effects cancel out, then overconfidence has no impact on an overconfident player's payoff.

We also find that the estimate for $\beta_{4}$ is negative and significant which indicates that, on average, the payoff of an underconfident player is lower than that of an unbiased high-skill player (hypothesis $6 \mathrm{~b}$ ). Underconfidence has a negative direct effect on an underconfident player's payoff due to an optimization loss and also a negative strategic effect since it lowers the effort of the team partner.

Result 6: (a) All else equal, overconfidence has no significant impact on an overconfident player's ex-post payoff; (b) All else equal, underconfidence reduces the ex-post payoff of an underconfident player.

Including the control variables the effects persist. All effects are significant at $1 \%$, except the impact of own overconfidence on payoff, which is insignificant. The only significant control variables are age, marital status and years of education: all else equal, older subjects attain higher payoffs than younger ones, single subjects attain higher payoffs than those who live in a couple, and subjects with more years of education attain higher payoffs than those with less.

\subsection{Information Treatments}

The team game includes two treatments that differ in the information provided to the subjects about their team partners. In treatment "Belief", subjects are only told their partners' subjective belief about skill. In treatment "Type and Belief", subjects are told their partners' subjective belief about skill and actual skill. For a subject who plays an equilibrium effort level, the only relevant information about the partner that the subject needs to make an effort choice is the partner's belief. So, in treatment "Type and Belief" knowing the type of the partner should not matter for the effort decision of a subjects who plays according to equilibrium. Therefore we expect behavior to be the same across the two information treatments. We now summarize 
the findings obtained when we analyze effort choices and payoffs in the two information treatments (the estimations are available upon request).

Result 7: (a) There is support for positive direct and strategic effects of overconfidence on effort in treatment "Belief" but not in "Type and Belief"; (b) There is support for negative direct and strategic effects of underconfidence on effort in both treatments; (c) The impact of self-confidence biases on players' payoffs is the same in the two treatments and follows hypotheses 5 and 6 ; (d) $58 \%$ of teams play a BNE in treatment "Belief" but only $46 \%$ of teams do it in "Type and Belief".

The fact that we find support for the existence of positive direct and strategic effects of overconfidence in treatment "Belief" but not in treatment "Type and Belief" is driven by differences in the percentage of teams that play a BNE across the two treatments. Whereas $58 \%$ of teams play a BNE in treatment "Belief" only $46 \%$ of teams do it in treatment "Type and Belief" -this difference is significant at $1 \%(p=0.0006)$. Moreover, restricting attention to teams where at least one player is overconfident, the difference is even larger: $62 \%$ of those teams play a BNE in treatment "Belief" and only $38 \%$ do that in treatment "Type and Belief" $(p<0.0001)$. The low effort levels provided by overconfident players who do not play a BNE explains this difference in behavior observed in treatments "Belief" and "Type and Belief."

\section{Discussion}

Our results show self-confidence influences effort provision in teams. Overconfidence increases effort provision which reduces moral hazard problems in teams. In contrast, underconfidence lowers effort provision. Both effects derive from the assumption that effort and skill are complements in production and the assumption that players' effort choices are strategic complements.

The positive direct effect of overconfidence on effort provision derives from the assumption that skill and effort are complements in production. If skill and effort are substitutes, then there could be a negative direct effect of overconfidence on effort provision.

Our findings would be strengthened if the marginal disutility of effort is decreasing in skill, that is, if high-skill players bear a lower cost of effort than low-skill players at any given effort level. As Gervais and Goldstein (2007) 
point out, this assumption is made in many models that allow for skill heterogeneity like signaling (Spence (1973)), rank-order tournaments (Lazear and Rosen (1981)), screening (Garen (1985)) or multi-period contracting (Lewis and Sappington (1997)).

The positive strategic effect of overconfidence of player $i$ on the effort of player $j$ derives from the assumption of complementarities between team partners' efforts which is natural in a teamwork model. If there are no complementarities in effort choices, then the strategic effect of self-confidence would not exist since each player would choose his effort level regardless of team partner's effort. As Alchian and Demsetz (1972) point out, firms are set up in order to make the most of positive externalities and complementarities between workers. Without complementarities in effort choices, teamwork is unlikely to be used as management practice because it leads to lower production level than individual work.

Social preferences have been shown to influence players' contributions in public good provision experiments. Peer pressure, cooperative social norms, reciprocity and altruism have been shown to affect effort choices in teams. The role of social pressure in teamwork is discussed by Kandel and Lazear (1992). Rotemberg (1994) shows that altruism can improve team outcomes when workers' payments depend only on their joint output.

Could it be that our findings stem from social preferences instead of self-confidence? Our experimental design rules out most of these alternative explanations. Players never know the identity of their partners and so no peer pressure can be exert in teams. Moreover, we use a perfect stranger matching design so that there are no repeated interactions between players. That rules out the establishment of cooperative social norms. Similarly, we believe that reciprocity cannot explain our results since players make simultaneous effort decisions, which reduces the scope for reciprocity concerns to play a role. However, we cannot rule out the possibility that altruism is an alternative explanation for the behavior of overconfident players (but is inconsistent with the behavior of underconfident players).

In the experiment, players are divided into two types according to their relative performance within a pair. In other words, the assignment of subjects to types is based on performance in a randomly drawn pair and not on a population ranking among the 20 participants in each session. Consequently, some players can be assigned to low types while their population rank is above median and others can be assigned to high types while their population rank is below median. In fact, we find that $27 \%$ of participants (32 subjects) 
are not assigned to the same type when we compare the assignment rule based on relative performance within a pair to the assignment rule based on population ranking among the 20 participants in each session. To make sure our findings do not depend on the way types are assigned, we perform the full analysis only for players who are assigned the same type whatever the assignment rule (the estimations are available upon request). We find essentially the same results. Hence, the assignment process does not seem to affect substantially our results.

\section{Conclusion}

This paper investigates experimentally the impact of agents' self-perceptions of skill on team performance. Teamwork is well known to lead to a free riding problem and inefficient production levels. However, previous research shows that psychological characteristics of agents like altruism and reciprocity can improve team outcomes.

We find that, all else equal, overconfident players provide higher effort levels than unbiased players. We also find empirical support for a strategic effect of overconfidence in that players put more effort when their team partner is overconfident rather than unbiased. As a consequence, the presence of overconfident players in teams leads to higher production levels. Additionally we find that overconfidence has no significant effect on an overconfident player's payoff and it raises the payoff of the team partners. Therefore, overconfidence generates a Pareto improvement. In contrast, underconfidence reduces players' efforts, team production and players' payoffs.

Our results show that the presence of overconfident workers in teams is beneficial for firms since it improves team production. Additionally, the findings also show that this can also be beneficial for workers since overconfidence does not damage overconfident workers' payoffs and improves the payoffs of their team partners. This advocates a hiring policy in which managers of firms take into account the employees' self-confidence in order to set up more efficient teams.

This first empirical study on self-perceptions and teamwork opens the door for further research. It would be interesting to run a similar experiment with a real effort task. Since real effort is typically hard to measure it would not be possible to test for direct and strategic effects of self-confidence on

effort. However, it would still be possible to find out if overconfident teams 
do better than unbiased teams and to study the effects of self-confidence on players' payoffs.

Our experimental design does not test all predictions in Gervais and Goldstein (2007). In particular, what are the implications of overconfidence for leadership in teams? Are overconfident people better leaders than those who evaluate their skills correctly? The impact of self-confidence on team output might also matter for endogenous team formation. Do people prefer to work with overconfident or unbiased partners? If people can exclude someone from a team, are underconfident workers more likely to be excluded than others?

\section{Acknowledgments}

We are grateful for comments from Laurent Denant-Boemont, Christoph Engel, Lorenz Goette, Rafael Lalive, Stéphane Robin, Marie Claire Villeval, and Christian Zehnder. We are also grateful to participants at the 5th Nordic Conference on Behavioural and Experimental Economics in Helsinki, Workshop on Experimental Methods and Economic Modelling in Capua, Economic Science Association European Conference in Luxembourg, and at Micro Workshop at University of Lausanne. We also thank Sylvain Ferriol for programming the software used in the experiment. 


\section{References}

Alchian, A.A., and H. Demsetz. 1972. "Production, Information Costs, and Economic Organization." American Economic Review 62:777-95.

Andolfatto, D., S. Mongrain, and G. Myers. 2009. "Rational truth-avoidance and self-esteem." Canadian Journal of Economics 42:141-154.

Baker, G.P., M.C. Jensen, and K.J. Murphy. 1988. "Compensation and Incentives: Practice vs. Theory." Journal of Finance 43:593-616.

Bénabou, R., and J. Tirole. 2003. "Intrinsic and Extrinsic Motivation." Review of Economic Studies 70:489-520.

—. 2002. "Self-Confidence and Personal Motivation." The Quarterly Journal of Economics 117:871-915.

Benoît, J.P., and J. Dubra. 2011. "Apparent Overconfidence?" Econometrica, forthcoming.

Bornstein, G., I. Erev, and R. Galili. 1993. "Constructive intergroup competition as a solution to the free rider problem: a field experiment." Journal of Experimental Social Psychology 29:463-478.

Bornstein, G., I. Erev, and O. Rozen. 1990. "Intergroup competition as a structural solution for social dilemma." Social Behaviour 5:247-260.

Burks, S.V., J.P. Carpenter, L. Goette, and A. Rustichini. 2010. "Overconfidence is a Social Signaling Bias." IZA Discussion Papers No. 4840.

Camerer, C.F., T.H. Ho, and J.K. Chong. 2004. "A Cognitive Hierarchy Model of Games." The Quarterly Journal of Economics 119:861-898.

Camerer, C.F., and D. Lovallo. 1999. "Overconfidence and Excess Entry: An Experimental Approach." American Economic Review 89:306-318.

Capelli, P., and N. Rogovsky. 1994. "New work systems and skill requirements." International Labour Review 133:205-220.

Clark, J.E., and L. Friesen. 2009. "Overconfidence in Forecasts of Own Performance: An Experimental Study." Economic Journal 119:229-251. 
Cohen, S., and D. Bailey. 1997. "What Makes Teams Work: Group Effectiveness Research from the Shop Floor to the Executive Suite." Journal of Management 23:239-290.

Compte, O., and A. Postlewaite. 2004. "Confidence-Enhanced Performance." American Economic Review 94:1536-1557.

Costa-Gomes, M., V.P. Crawford, and B. Broseta. 2001. "Cognition and Behavior in Normal-Form Games: An Experimental Study." Econometrica 69:1193-1235.

Falk, A., and A. Ichino. 2006. "Clean Evidence On Peer Pressure." Journal of Labor Economics 24:39-57.

Fang, H., and G. Moscarini. 2005. "Morale hazard." Journal of Monetary Economics 52:749-777.

Fehr, E., and U. Fischbacher. 2004. "Third-party punishment and social norms." Evolution and Human Behavior 25:63-87.

Fehr, E., and S. Gächter. 2000. "Cooperation and Punishment in Public Goods Experiments." American Economic Review 90:980-994.

Fischbacher, U., S. Gächter, and E. Fehr. 2001. "Are people conditionally cooperative? Evidence from a public goods experiment." Economics Letters $71: 397-404$.

Garen, J.E. 1985. "Worker Heterogeneity, Job Screening, and Firm Size." Journal of Political Economy 93:715-39.

Gervais, S., and I. Goldstein. 2007. "The Positive Effects of Biased SelfPerceptions in Firms." Review of Finance 11:453-496.

Gordon, J. 1992. "Work teams: How far have we come?" Training 29:59-65.

Grieco, D., and R.M. Hogarth. 2009. "Overconfidence in absolute and relative performance: The regression hypothesis and Bayesian updating." Journal of Economic Psychology 30:756-771.

Gunnthorsdottir, A., and A. Rapoport. 2006. "Embedding social dilemmas in intergroup competition reduces free-riding." Organizational Behavior and Human Decision Processes 101:184-199. 
Hoelzl, E., and A. Rustichini. 2005. "Overconfident: Do You Put Your Money On It?" Economic Journal 115:305-318.

Holmström, B. 1982. "Moral Hazard in Teams." Bell Journal of Economics 13:324-340.

Hvide, H.K. 2002. "Pragmatic beliefs and overconfidence." Journal of Economic Behavior 65 Organization 48:15-28.

Ivanova-Stenzel, R., and D. Kübler. 2005. "Courtesy and Idleness: Gender Differences in Team Work and Team Competition." SFB Discussion Papers No. 91.

Kandel, E., and E. Lazear. 1992. "Peer Pressure and Partnerships." Journal of Political Economy 100:801-817.

Knez, M., and D. Simester. 2001. "Firm-Wide Incentives and Mutual Monitoring at Continental Airlines." Journal of Labor Economics 19:743-72.

Köszegi, B. 2006. "Ego Utility, Overconfidence, and Task Choice." Journal of the European Economic Association 4:673-707.

Larwood, L., and W. Whittaker. 1977. "Managerial myopia: Self-serving biases in organizational planning." Journal of Applied Psychology 62:194 $-198$.

Lavy, V. 2002. "Evaluating the Effect of Teachers' Group Performance Incentives on Pupil Achievement." Journal of Political Economy 110:1286-1317.

Lawler, E., S. Mohrman, and G. Ledford. 1995. Creating high performance organizations: practices and results of employee involvement and total quality management in Fortune 1000 companies, 2nd Edition, ed. Jossey-Bass Inc Pub.

Lazear, E.P., and S. Rosen. 1981. "Rank-Order Tournaments as Optimum Labor Contracts." The Journal of Political Economy 89:841-864.

Lazear, E.P., and K.L. Shaw. 2007. "Personnel Economics: The Economist's View of Human Resources." The Journal of Economic Perspectives 21:91114. 
Lewis, T.R., and D.E.M. Sappington. 1997. "Penalizing Success in Dynamic Incentive Contracts: No Good Deed Goes Unpunished?" The RAND Journal of Economics 28:346-358.

Malmendier, U., and G. Tate. 2005. "CEO Overconfidence and Corporate Investment." Journal of Finance 60:2661-2700.

Moore, D.A., and D.M. Cain. 2007. "Overconfidence and underconfidence: When and why people underestimate (and overestimate) the competition." Organizational Behavior and Human Decision Processes 103:197-213.

Myers, D. 1996. Social Psychology. New York: McGraw-Hill.

Nagel, R. 1995. "Unraveling in Guessing Games: An Experimental Study." American Economic Review 85:1313-1326.

Nalbantian, H.R., and A. Schotter. 1997. "Productivity under Group Incentives: An Experimental Study." American Economic Review 87:314-341.

Park, Y., and L. Santos-Pinto. 2010. "Overconfidence in tournaments: evidence from the field." Theory and Decision 69:143-166.

Rotemberg, J.J. 1994. "Human Relations in the Workplace." Journal of Political Economy 102:684-717.

Santos-Pinto, L. 2008. "Positive Self-image and Incentives in Organisations." The Economic Journal 118:1315-1332.

—. 2010. "Positive Self-Image In Tournaments." International Economic Review 51:475-496.

Sherstyuk, K., O. Hill, M. Dowling, and L. Ma. 2002. "Altruism and voluntary provision of public goods." Economics Bulletin 3:1-8.

Smith, A. 1976. An Inquiry into the Nature and Causes of the Wealth of Nations. Chicago: The University of Chicago Press, originally published in 1776 .

Spence, A.M. 1973. "Job Market Signaling." The Quarterly Journal of Economics 87:355-374. 
Stahl, D.O., and P.W. Wilson. 1995. "On Players' Models of Other Players: Theory and Experimental Evidence." Games and Economic Behavior 10:218-254.

Svenson, O. 1981. "Are we all less risky and more skillful than our fellow drivers?" Acta Psychologica 47:143-148.

Taylor, S., and J. Brown. 1988. "Illusion and well-being: a social psychological perspective on mental health." Psychological Bulletin 103:193-210.

Weinberg, B.A. 2009. "A Model of Overconfidence." IZA Discussion Papers No. 4285. 


\section{Tables}

Table 1: Sample Characteristics

\begin{tabular}{lcccccc}
\hline \hline & \multicolumn{2}{c}{$\begin{array}{c}\text { Full } \\
\text { Sample }\end{array}$} & \multicolumn{2}{c}{$\begin{array}{c}\text { Treatment } \\
\text { "Belief" }\end{array}$} & \multicolumn{2}{c}{$\begin{array}{c}\text { Treatment } \\
\text { "Type and Belief" }\end{array}$} \\
\hline Gender & Mean & Std dev & Mean & Std dev & Mean & Std dev \\
Age & 0.56 & 0.50 & 0.50 & 0.50 & 0.62 & 0.49 \\
Marital status & 22.14 & 4.62 & 21.52 & 2.00 & 22.77 & 6.11 \\
Student & 0.08 & 0.26 & 0.10 & 0.30 & 0.05 & 0.22 \\
Years of education & 0.92 & 0.28 & 0.92 & 0.28 & 0.92 & 0.28 \\
Field of study & 3.13 & 1.33 & 2.92 & 1.23 & 3.35 & 1.41 \\
Children & 0.76 & 0.43 & 0.80 & 0.40 & 0.72 & 0.45 \\
Years of education of mother & 0.02 & 0.13 & 0.02 & 0.13 & 0.02 & 0.13 \\
Years of education of father & 2.69 & 1.70 & 2.72 & 1.78 & 2.67 & 1.63 \\
Participation in experiments & 3.43 & 2.06 & 3.18 & 1.97 & 3.68 & 2.13 \\
Observations & 0.93 & 0.25 & 0.93 & 0.25 & 0.93 & 0.25 \\
\hline \hline
\end{tabular}

Note. Gender is 0 if male and 1 if female. Marital status is 0 if single and 1 if couple. Student is 1 if student and 0 otherwise. Years of education is 1 if complete secondary school, 2 if you have 2 years of university, 3 if three years at university, 4 if four years, 5 if five years, and 6 if six or more years of university. Field of study is 1 if economics and management and 0 otherwise. Children is 1 if at least one child and 0 otherwise. Participation in experiments is 1 if previously participated and 0 if not.

Table 2: Summary Statistics on Self-Confidence Biases

\begin{tabular}{|c|c|c|c|c|}
\hline & Skill & Belief & Players & Proportion \\
\hline \multirow{4}{*}{$\begin{array}{c}\text { Full } \\
\text { Sample }\end{array}$} & High & Unbiased & 38 & $31.67 \%$ \\
\hline & & Underconfident & 22 & $18.33 \%$ \\
\hline & Low & Unbiased & 28 & $23.33 \%$ \\
\hline & & Overconfident & 32 & $26.67 \%$ \\
\hline \multirow{4}{*}{$\begin{array}{l}\text { Treatment } \\
\text { "Belief" }\end{array}$} & High & Unbiased & 18 & $30.00 \%$ \\
\hline & & Underconfident & 12 & $20.00 \%$ \\
\hline & Low & Unbiased & 15 & $25.00 \%$ \\
\hline & & Overconfident & 15 & $25.00 \%$ \\
\hline \multirow{4}{*}{$\begin{array}{c}\text { Treatment } \\
\text { "Type and Belief" }\end{array}$} & High & Unbiased & 20 & $33.33 \%$ \\
\hline & & Underconfident & 10 & $16.67 \%$ \\
\hline & Low & Unbiased & 13 & $21.67 \%$ \\
\hline & & Overconfident & 17 & $28.33 \%$ \\
\hline
\end{tabular}


Table 3: Set of BNE Effort Levels, $\Gamma\left(q_{1}, q_{2}\right)$

\begin{tabular}{|c|c|c|c|}
\hline \multirow{4}{*}{ Player 1} & & \multicolumn{2}{|c|}{ Player 2} \\
\hline & & $q_{2} \leq 0.5$ & $q_{2} \geq 0.5$ \\
\hline & $q_{1} \leq 0.5$ & $\begin{array}{c}\{(6,6),(8,6),(6,8) \\
\quad(8,8),(10,10)\}\end{array}$ & $\begin{array}{c}\{(6,8),(8,8),(8,10) \\
(10,10),(10,12)\}\end{array}$ \\
\hline & $q_{1} \geq 0.5$ & $\begin{array}{c}\{(8,6),(8,8),(10,8), \\
(10,10),(12,10)\}\end{array}$ & $\begin{array}{c}\{(8,8),(10,10),(12,10), \\
\quad(10,12),(12,12)\}\end{array}$ \\
\hline
\end{tabular}

Table 4: Teams that Play a BNE as a Function of Skills and Beliefs

\begin{tabular}{lcccc}
\hline \hline & Low-Skill & Mixed-Skill & High-Skill & Total \\
\hline Player $i$ underconfident & & & $16 / 29$ & $16 / 29$ \\
Player $j$ underconfident & & & $(0.55)$ & $(0.55)$ \\
& & & & \\
Player $i$ underconfident & & $33 / 74$ & $36 / 96$ & $69 / 170$ \\
Player $j$ unbiased & & $(0.45)$ & $(0.37)$ & $(0.41)$ \\
& & & & \\
Player $i$ unbiased & $28 / 42$ & $54 / 122$ & $74 / 85$ & $156 / 249$ \\
Player $j$ unbiased & $(0.67)$ & $(0.44)$ & $(0.87)$ & $(0.63)$ \\
& & & & \\
Player $i$ underconfident & & $39 / 80$ & & $(0.49)$ \\
Player $j$ overconfident & & $(0.49)$ & & $133 / 256$ \\
Player $i$ unbiased & $44 / 112$ & $89 / 144$ & & $(0.52)$ \\
Player $j$ overconfident & $(0.39)$ & $(0.62)$ & & $21 / 56$ \\
& & & & $(0.37)$ \\
Player $i$ overconfident & $21 / 56$ & & & \\
Player $j$ overconfident & $(0.37)$ & & & $(0.52)$ \\
Total & & & & \\
& $93 / 210$ & $215 / 420$ & $126 / 210$ & $434 / 840$ \\
\hline \hline
\end{tabular}

Note. In parentheses is the proportion of teams that play a BNE for each team composition. 
Table 5: Distribution of Effort as a Function of Skills and Beliefs

\begin{tabular}{|c|c|c|c|c|c|c|c|c|c|c|}
\hline \multirow[b]{3}{*}{ Effort } & & & \multicolumn{8}{|c|}{ Team partner's belief } \\
\hline & & & \multicolumn{4}{|c|}{ Low } & \multicolumn{4}{|c|}{ High } \\
\hline & & & 6 & 8 & 10 & 12 & 6 & 8 & 10 & 12 \\
\hline \multirow{4}{*}{ Player } & Low- & Unbiased & 0.39 & 0.42 & 0.13 & 0.06 & 0.20 & 0.41 & 0.17 & 0.22 \\
\hline & Skill & Overconfident & 0.14 & 0.20 & 0.43 & 0.23 & 0.14 & 0.16 & 0.29 & 0.41 \\
\hline & High- & Unbiased & 0.07 & 0.18 & 0.47 & 0.28 & 0.03 & 0.11 & 0.32 & 0.54 \\
\hline & Skill & Underconfident & 0.33 & 0.23 & 0.32 & 0.12 & 0.26 & 0.52 & 0.11 & 0.11 \\
\hline
\end{tabular}


Table 6: Regression Results: Individual Effort Choices

\begin{tabular}{|c|c|c|c|c|}
\hline Player's belief & $\begin{array}{c}0.946^{a} \\
(0.167)\end{array}$ & $\begin{array}{c}0.842^{a} \\
(0.183)\end{array}$ & & \\
\hline Team partner's belief & $\begin{array}{c}0.352^{a} \\
(0.082)\end{array}$ & $\begin{array}{c}0.381^{a} \\
(0.082)\end{array}$ & & \\
\hline Player's skill & & & $\begin{array}{l}1.099^{a} \\
(0.205)\end{array}$ & $\begin{array}{c}0.950^{a} \\
(0.221)\end{array}$ \\
\hline Team partner's skill & & & $\begin{array}{c}0.515^{a} \\
(0.103)\end{array}$ & $\begin{array}{c}0.542^{a} \\
(0.103)\end{array}$ \\
\hline Overconfident player & & & $\begin{array}{c}0.742^{a} \\
(0.220)\end{array}$ & $\begin{array}{c}0.648^{a} \\
(0.236)\end{array}$ \\
\hline Underconfident player & & & $\begin{array}{c}-1.152^{a} \\
(0.242)\end{array}$ & $\begin{array}{c}-1.034^{a} \\
(0.252)\end{array}$ \\
\hline Overconfident team partner & & & $\begin{array}{c}0.175^{c} \\
(0.098)\end{array}$ & $\begin{array}{c}0.185^{c} \\
(0.097)\end{array}$ \\
\hline Underconfident team partner & & & $\begin{array}{c}-0.505^{a} \\
(0.102)\end{array}$ & $\begin{array}{c}-0.550^{a} \\
(0.106)\end{array}$ \\
\hline Gender & & $\begin{array}{c}-0.307^{c} \\
(0.163)\end{array}$ & & $\begin{array}{l}-0.290^{c} \\
(0.163)\end{array}$ \\
\hline Age & & $\begin{array}{c}-0.023^{b} \\
(0.011)\end{array}$ & & $\begin{array}{l}-0.020^{c} \\
(0.011)\end{array}$ \\
\hline Marital status & & $\begin{array}{c}0.113 \\
(0.222)\end{array}$ & & $\begin{array}{c}0.093 \\
(0.218)\end{array}$ \\
\hline Student & & $\begin{array}{c}-0.222 \\
(0.259)\end{array}$ & & $\begin{array}{c}-0.227 \\
(0.258)\end{array}$ \\
\hline Years of education & & $\begin{array}{c}-0.027 \\
(0.053)\end{array}$ & & $\begin{array}{c}-0.027 \\
(0.053)\end{array}$ \\
\hline Field of study & & $\begin{array}{c}-0.091 \\
(0.206)\end{array}$ & & $\begin{array}{c}-0.125 \\
(0.211)\end{array}$ \\
\hline Children & & $\begin{array}{c}-0.945 \\
(0.692)\end{array}$ & & $\begin{array}{c}-0.951 \\
(0.710)\end{array}$ \\
\hline Years of education of mother & & $\begin{array}{l}-0.003 \\
(0.055)\end{array}$ & & $\begin{array}{c}0.005 \\
(0.055)\end{array}$ \\
\hline Years of education of father & & $\begin{array}{c}0.054 \\
(0.041)\end{array}$ & & $\begin{array}{c}0.050 \\
(0.041)\end{array}$ \\
\hline Participation in experiments & & $\begin{array}{c}-0.171 \\
(0.304)\end{array}$ & & $\begin{array}{c}-0.202 \\
(0.293)\end{array}$ \\
\hline Observations & 1680 & 1680 & 1680 & 1680 \\
\hline Subjects & 120 & 120 & 120 & 120 \\
\hline Log-likelihood & -2132.069 & -2097.885 & -2107.988 & -2076.584 \\
\hline Chi squared & 45.56 & 62.05 & 69.40 & 81.11 \\
\hline Prob $>$ Chi Squared & 0.0000 & 0.0000 & 0.0000 & 0.0000 \\
\hline Pseudo R squared & 0.0712 & 0.0861 & 0.0817 & 0.0954 \\
\hline
\end{tabular}

Note. Clustered standard errors in parentheses. Superscripts $a, b$ and $c$ indicate significance at $1 \%, 5 \%$ and $10 \%$ level, respectively. 
Table 7: Mean Team Output as a Function of Team Skills, Beliefs, and Compliance with BNE.

\begin{tabular}{lccc}
\hline \hline & Low-Skill & Mixed-Skill & High-Skill \\
\hline Player $i$ underconfident & & & 882 \\
Player $j$ underconfident & & & $(29)$ \\
& & 664 & 986 \\
Player $i$ underconfident & & $(74)$ & $(96)$ \\
Player $j$ unbiased & & & \\
& 422 & 792 & 1231 \\
Player $i$ unbiased & $(42)$ & $(122)$ & $(85)$ \\
Player $j$ unbiased & & & \\
Player $i$ underconfident & & $(804)$ & \\
Player $j$ overconfident & & & \\
Player $i$ unbiased & 538 & 890 & \\
Player $j$ overconfident & $(112)$ & $(144)$ & \\
& & & \\
Player $i$ overconfident & 563 & & \\
Player $j$ overconfident & $(56)$ & & $(210)$ \\
Total & & & \\
& 521 & 783 & \\
\hline \hline
\end{tabular}

Note. In parentheses is the number of teams in each category. 
Table 8: Regression Results: Team Output

\begin{tabular}{|c|c|c|c|c|c|c|}
\hline \multirow[b]{2}{*}{ Intercept } & \multicolumn{2}{|c|}{ Low-Skill Teams } & \multicolumn{2}{|c|}{ Mixed-Skill Teams } & \multicolumn{2}{|c|}{ High-Skill Teams } \\
\hline & $\begin{array}{l}421.714^{a} \\
(11.825)\end{array}$ & $\begin{array}{l}529.633^{a} \\
(72.069)\end{array}$ & $\begin{array}{l}792.541^{a} \\
(13.474)\end{array}$ & $\begin{array}{r}871.042^{a} \\
(58.573)\end{array}$ & $\begin{array}{c}1230.847^{a} \\
(14.478)\end{array}$ & $\begin{array}{l}835.461^{a} \\
(257.093)\end{array}$ \\
\hline Two under & & & & & $\begin{array}{c}-349.054^{a} \\
(40.107)\end{array}$ & $\begin{array}{c}-366.577^{a} \\
(40.564)\end{array}$ \\
\hline One under & & & $\begin{array}{r}-127.946^{a} \\
(21.495)\end{array}$ & $\begin{array}{c}-124.950^{a} \\
(21.611)\end{array}$ & $\begin{array}{c}-245.118^{a} \\
(22.641)\end{array}$ & $\begin{array}{r}-257.259^{a} \\
(24.202)\end{array}$ \\
\hline Two over & $\begin{array}{c}141.321^{a} \\
(19.719)\end{array}$ & $\begin{array}{l}111.992^{a} \\
(24.235)\end{array}$ & & & & \\
\hline One over & $\begin{array}{c}117^{a} \\
(16.140)\end{array}$ & $\begin{array}{c}97.490^{a} \\
(17.225)\end{array}$ & $\begin{array}{c}97.709^{a} \\
(18.803)\end{array}$ & $\begin{array}{l}82.618^{a} \\
(20.177)\end{array}$ & & \\
\hline Two biased & & & $\begin{array}{c}-108.366^{a} \\
(19.111)\end{array}$ & $\begin{array}{c}-108.134^{a} \\
(19.654)\end{array}$ & & \\
\hline Mixed gender & & $\begin{array}{c}-21.274 \\
(24.183)\end{array}$ & & $\begin{array}{l}-46.204^{b} \\
(19.500)\end{array}$ & & $\begin{array}{c}22.338 \\
(25.173)\end{array}$ \\
\hline Female gender & & $\begin{array}{l}-37.335 \\
(25.545)\end{array}$ & & $\begin{array}{l}-60.520^{a} \\
(22.805)\end{array}$ & & $\begin{array}{c}19.834 \\
(35.979)\end{array}$ \\
\hline Age & & $\begin{array}{c}0.392 \\
(1.439)\end{array}$ & & $\begin{array}{l}-2.250^{b} \\
(1.103)\end{array}$ & & $\begin{array}{l}4.545 \\
(6.446)\end{array}$ \\
\hline One married player & & $\begin{array}{l}-42.222^{c} \\
(22.494)\end{array}$ & & $\begin{array}{c}21.169 \\
(25.126)\end{array}$ & & $\begin{array}{c}-55.538 \\
(54.614)\end{array}$ \\
\hline Two married players & & $\begin{array}{c}-3.515 \\
(34.085)\end{array}$ & & $\begin{array}{r}-124.564^{b} \\
(49.273)\end{array}$ & & \\
\hline Student & & $\begin{array}{l}-29.174 \\
(25.637)\end{array}$ & & $\begin{array}{c}-2.881 \\
(22.784)\end{array}$ & & $\begin{array}{l}-15.132 \\
(43.871)\end{array}$ \\
\hline Players' years of education & & $\begin{array}{l}-7.347 \\
(4.939)\end{array}$ & & $\begin{array}{c}1.502 \\
(3.574)\end{array}$ & & $\begin{array}{l}14.391^{b} \\
(6.573)\end{array}$ \\
\hline No student in economics & & $\begin{array}{c}-69.159 \\
(48.309)\end{array}$ & & $\begin{array}{c}38.417 \\
(30.823)\end{array}$ & & $\begin{array}{l}-31.850 \\
(41.307)\end{array}$ \\
\hline One student in economics & & $\begin{array}{c}16.461 \\
(17.685)\end{array}$ & & $\begin{array}{c}20.037 \\
(15.627)\end{array}$ & & $\begin{array}{c}34.318 \\
(23.422)\end{array}$ \\
\hline Child & & $\begin{array}{l}-57.065 \\
(36.657)\end{array}$ & & $\begin{array}{l}-35.380 \\
(52.805)\end{array}$ & & \\
\hline Mothers' years of education & & $\begin{array}{l}-2.486 \\
(3.463)\end{array}$ & & $\begin{array}{c}2.680 \\
(3.634)\end{array}$ & & $\begin{array}{c}4.819 \\
(6.050)\end{array}$ \\
\hline Fathers' years of education & & $\begin{array}{c}-3.282 \\
(2.770)\end{array}$ & & $\begin{array}{c}4.361 \\
(2.991)\end{array}$ & & $\begin{array}{l}10.930^{b} \\
(4.559)\end{array}$ \\
\hline Participation in experiment & & $\begin{array}{l}-13.096 \\
(21.343) \\
\end{array}$ & & $\begin{array}{l}-15.507 \\
(22.903) \\
\end{array}$ & & $\begin{array}{c}40.891 \\
(35.548) \\
\end{array}$ \\
\hline Observations & 210 & 210 & 420 & 420 & 210 & 210 \\
\hline $\mathrm{F}$ & 36.10 & 8.18 & 55.53 & 14.75 & 78.93 & 19.74 \\
\hline Prob $>F$ & 0.0000 & 0.0000 & 0.0000 & 0.0000 & 0.0000 & 0.0000 \\
\hline $\mathrm{R}$ squared & 0.1795 & 0.2593 & 0.2816 & 0.3166 & 0.4196 & 0.4949 \\
\hline
\end{tabular}

Note. Robust standard errors in parentheses. Superscripts $a, b$ and $c$ indicate significance at 1\%, $5 \%$ and $10 \%$ level, respectively. 
Table 9: Mean individual payoff as a function of players' skill, belief, and partners' skill and belief

\begin{tabular}{lllcccc}
\hline \hline & & \multicolumn{3}{c}{ Team partner's skill and belief } \\
& & & \multicolumn{2}{c}{ Low-Skill } & \multicolumn{2}{c}{ High-Skill } \\
& & Unbiased & Overconfident & Unbiased & Underconfident \\
\hline \multirow{5}{*}{ Player } & Low- & Unbiased & 119 & 148 & 271 & 235 \\
& skill & Overconfident & 126 & 140 & 278 & 203 \\
& & & & & \\
& High- & Unbiased & 246 & 280 & 430 & 338 \\
& Skill & Underconfident & 217 & 245 & 381 & 329 \\
\hline \hline
\end{tabular}


Table 10: Regression Results: Individual Payoffs

\begin{tabular}{|c|c|c|}
\hline Intercept & $\begin{array}{c}119.51^{a} \\
(3.56)\end{array}$ & $\begin{array}{l}86.04^{a} \\
(12.40)\end{array}$ \\
\hline Player's skill & $\begin{array}{c}133.93^{a} \\
(4.41)\end{array}$ & $\begin{array}{c}136.30^{a} \\
(4.24)\end{array}$ \\
\hline Team partner's skill & $\begin{array}{c}164.14^{a} \\
(3.07)\end{array}$ & $\begin{array}{c}163.88^{a} \\
(3.11)\end{array}$ \\
\hline Overconfident player & $\begin{array}{l}-3.89 \\
(4.32)\end{array}$ & $\begin{array}{l}-3.05 \\
(4.38)\end{array}$ \\
\hline Underconfident player & $\begin{array}{c}-33.26^{a} \\
(4.54)\end{array}$ & $\begin{array}{c}-35.18^{a} \\
(4.70)\end{array}$ \\
\hline Overconfident team partner & $\begin{array}{c}26.26^{a} \\
(3.61)\end{array}$ & $\begin{array}{c}25.93^{a} \\
(3.60)\end{array}$ \\
\hline Underconfident team partner & $\begin{array}{c}-66.53^{a} \\
(5.07)\end{array}$ & $\begin{array}{c}-66.30^{a} \\
(5.11)\end{array}$ \\
\hline Gender & & $\begin{array}{c}4.31 \\
(3.20)\end{array}$ \\
\hline Age & & $\begin{array}{c}0.72^{a} \\
(0.22)\end{array}$ \\
\hline Marital status & & $\begin{array}{r}-12.08^{a} \\
(3.02)\end{array}$ \\
\hline Student & & $\begin{array}{c}2.36 \\
(5.12)\end{array}$ \\
\hline Years of education & & $\begin{array}{c}2.53^{b} \\
(1.12)\end{array}$ \\
\hline Field of study & & $\begin{array}{l}-3.92 \\
(3.44)\end{array}$ \\
\hline Children & & $\begin{array}{c}12.33 \\
(10.25)\end{array}$ \\
\hline Years of education of mother & & $\begin{array}{c}0.40 \\
(0.97)\end{array}$ \\
\hline Years of education of father & & $\begin{array}{c}0.04 \\
(0.92)\end{array}$ \\
\hline Participation in experiments & & $\begin{array}{c}7.10 \\
(5.65)\end{array}$ \\
\hline Observations & 1680 & 1680 \\
\hline Subjects & 120 & 120 \\
\hline $\mathrm{F}$ & 760.96 & 338.80 \\
\hline Prob $>F$ & 0.0000 & 0.0000 \\
\hline R squared & 0.7568 & 0.7594 \\
\hline
\end{tabular}

Note. Clustered standard errors in parentheses. Superscripts $a, b$ and $c$ indicate significance at $1 \%, 5 \%$ and $10 \%$ level, respectively. 


\section{Appendix A: Gervais and Goldstein (2007)'s Model}

According to Gervais and Goldstein (2007) team output generates from a single one-period project, which can either succeed, with probability $\pi$, or fail, with probability $1-\pi$. The value of the project is the value of its expected cash flow. The probability of success depends on the agents' unobservable efforts, $e_{i} \in[0,1]$, their abilities, $a_{i} \in[0,1]$, and a synergy effect. In particular,

$$
\pi\left(e_{1}, e_{2}\right)=a_{1} e_{1}+a_{2} e_{2}+s e_{1} e_{2},
$$

where $a_{1}+a_{2}+s<1$ so that success probabilities lie in [0,1], and $s>0$ so that agents' efforts create positive externalities. Agents are risk-neutral. Their effort decisions are made simultaneously and are unobservable to the other agent. They sustain a private cost of effort given by $c\left(e_{i}\right)=\frac{1}{2} e_{i}^{2}$. Agent $i$ chooses effort to maximize expected payoff,

$$
U_{i}=w_{i}\left(a_{i} e_{i}+a_{j} e_{j}+s e_{1} e_{2}\right)-\frac{1}{2} e_{i}^{2}, i \neq j .
$$

The optimal effort of agent $i$ as a function of agent $j$ 's effort is

$$
e_{i}=w_{i}\left(a_{i}+s e_{j}\right), i \neq j .
$$

The Nash equilibrium effort of agent $i$ is

$$
e_{i}=\frac{w_{i}\left(a_{i}+s w_{j} a_{j}\right)}{1-s^{2} w_{1} w_{2}} .
$$

To introduce overconfidence, Gervais and Goldstein (2007) assume that agent 2 suffers from a self-perception bias, thinking that he is more skilled than he really is, and therefore overestimates the contribution of his effort to the project's chance of success. Specifically, agent 2 thinks his ability is $A_{2} \geq a_{2}$, although it is actually only $a_{2}$.

Gervais and Goldstein (2007) denote the agent's self-perception bias by $b_{2}=A_{2}-a_{2} \in\left[0,1-a_{1}-a_{2}-s\right)$. They assume that agent 1 knows that agent 2 is biased, agent 2 is unaware of his own bias, and agent 2 knows that agent 1 thinks 2 is biased but disagrees with 1 . This implies that agent 2 chooses effort to maximize

$$
U_{2}=w_{2}\left[a_{1} e_{1}+\left(a_{2}+b_{2}\right) e_{2}+s e_{1} e_{2}\right]-\frac{1}{2} e_{2}^{2} .
$$


From this, it is easy to show that agent 1 and agent 2 choose

$$
\begin{aligned}
& e_{1}=w_{1}\left(a_{1}+s e_{2}\right), \\
& e_{2}=w_{2}\left(a_{2}+b_{2}+s e_{1}\right) .
\end{aligned}
$$

The Nash equilibrium effort levels are

$$
\begin{aligned}
& e_{1}=\frac{w_{1}\left(a_{1}+s w_{2} a_{2}\right)}{1-s^{2} w_{1} w_{2}}+\frac{b_{2} s w_{1} w_{2}}{1-s^{2} w_{1} w_{2}} \\
& e_{2}=\frac{w_{2}\left(a_{2}+s w_{1} a_{1}\right)}{1-s^{2} w_{1} w_{2}}+\frac{b_{2} w_{2}}{1-s^{2} w_{1} w_{2}} .
\end{aligned}
$$

From (11) and (12) we can see that agents' efforts are higher when agent 2 is overconfident than when agent 2 is unbiased. We also see that agents' efforts are increasing with overconfidence.

\section{Appendix B: Derivations}

Using the equilibrium effort levels $e_{1}$ and $e_{2}$ determined by (3), the ex-post payoff of player 1 is equal to

$\hat{U}_{1}\left(\bar{b}_{1}, \bar{b}_{2}\right)=w\left[a_{1} e_{1}\left(\bar{b}_{1}, \bar{b}_{2}\right)+a_{2} e_{2}\left(\bar{b}_{1}, \bar{b}_{2}\right)+s e_{1}\left(\bar{b}_{1}, \bar{b}_{2}\right) e_{2}\left(\bar{b}_{1}, \bar{b}_{2}\right)\right]-c\left[e_{1}\left(\bar{b}_{1}, \bar{b}_{2}\right)\right]^{2}$.

If player 1 is unbiased $\left(\bar{b}_{1}=0\right)$ and player 2 is overconfident $\left(\bar{b}_{2}>0\right)$, then the impact of $\bar{b}_{2}$ on $\hat{U}_{1}$ is given by

$$
\begin{aligned}
\frac{\partial \hat{U}_{1}}{\partial \bar{b}_{2}} & =\frac{\partial \hat{U}_{1}}{\partial e_{2}} \frac{\partial e_{2}}{\partial \bar{b}_{2}}+\frac{\partial \hat{U}_{1}}{\partial e_{1}} \frac{\partial e_{1}}{\partial \bar{b}_{2}} \\
& =w\left(a_{2}+s e_{1}\right) \frac{\partial e_{2}}{\partial \bar{b}_{2}}+w\left(a_{1}+s e_{2}\right) \frac{\partial e_{1}}{\partial \bar{b}_{2}}-2 c e_{1} \frac{\partial e_{1}}{\partial \bar{b}_{2}} \\
& =\frac{2 c w^{2}\left(a_{2}+s e_{1}\right)+s w^{3}\left(a_{1}+s e_{2}\right)-2 c e_{1} s w^{2}}{z} \\
& =\frac{2 c w^{2} a_{2}+s w^{3}\left(a_{1}+s e_{2}\right)}{z}>0
\end{aligned}
$$

Hence, if agent 1 is unbiased and agent 2 is overconfident, then an increase in overconfidence of agent 2 increases the ex-post payoff of agent 1 . Obviously, the reverse happens if agent 1 is unbiased and agent 2 is underconfident. 
If player 1 is overconfident $\left(\bar{b}_{1}>0\right)$ and player 2 is unbiased $\left(\bar{b}_{2}=0\right)$, then the impact of $\bar{b}_{1}$ on $\hat{U}_{1}$ is given by

$$
\begin{aligned}
\frac{\partial \hat{U}_{1}}{\partial \bar{b}_{1}} & =\frac{\partial \hat{U}_{1}}{\partial e_{1}} \frac{\partial e_{1}}{\partial \bar{b}_{1}}+\frac{\partial \hat{U}_{1}}{\partial e_{2}} \frac{\partial e_{2}}{\partial \bar{b}_{1}} \\
& =w\left(a_{1}+s e_{2}\right) \frac{\partial e_{1}}{\partial \bar{b}_{1}}-2 c e_{1} \frac{\partial e_{1}}{\partial \bar{b}_{1}}+w\left(a_{2}+s e_{1}\right) \frac{\partial e_{2}}{\partial \bar{b}_{1}} \\
& =\frac{2 c w^{2}\left(a_{1}+s e_{2}\right)-4 c^{2} w e_{1}+s w^{3} a_{2}+s^{2} e_{1} w^{3}}{z} \\
& =\frac{w\left[2 c w\left(a_{1}+s e_{2}\right)+s w^{2} a_{2}-z e_{1}\right]}{z}
\end{aligned}
$$

This is positive if

$$
2 c w\left(a_{1}+s e_{2}\right)+s w^{2} a_{2}>z e_{1} .
$$

We know that $e_{1}=2 \frac{c w}{z} \bar{a}_{1}+\frac{s w^{2}}{z} \bar{a}_{2}+2 \frac{c w}{z} \bar{b}_{1}$. So, the inequality becomes

$$
2 c w a_{1}+2 c w e_{2}+s w^{2} a_{2}>2 c w \bar{a}_{1}+s w^{2} \bar{a}_{2}+2 c w \bar{b}_{1}
$$

or

$$
2 c a_{1}+2 c s e_{2}+s w a_{2}>2 c \bar{a}_{1}+s w \bar{a}_{2}+2 c \bar{b}_{1}
$$

or

$$
\bar{b}_{1}<s e_{2}+\left(a_{1}-\bar{a}_{1}\right)+\frac{s w}{2 c}\left(a_{2}-\bar{a}_{2}\right)
$$

Substituting $e_{2}=2 \frac{c w}{z} \bar{a}_{2}+\frac{s w^{2}}{z} \bar{a}_{1}+\frac{s w^{2}}{z} \bar{b}_{1}$ we obtain

$$
\begin{gathered}
z \bar{b}_{1}<2 c w \bar{a}_{2}+s^{2} w^{2} \bar{a}_{1}+s^{2} w^{2} \bar{b}_{1}+z a_{1}-z \bar{a}_{1}+\frac{z s w}{2 c}\left(a_{2}-\bar{a}_{2}\right) \\
\left(4 c^{2}-2 s^{2} w^{2}\right) \bar{b}_{1}<s w\left(2 c-\frac{z}{2 c}\right) \bar{a}_{2}+z a_{1}-\left(4 c^{2}-2 s^{2} w^{2}\right) \bar{a}_{1}+\frac{z s w}{2 c} a_{2} \\
\left(4 c^{2}-2 s^{2} w^{2}\right) \bar{b}_{1}<\frac{s^{3} w^{3}}{2 c}\left(\bar{a}_{2}-a_{2}\right)+z\left(a_{1}-\bar{a}_{1}\right)+s^{2} w^{2} \bar{a}_{1}+2 s w c a_{2} \\
\bar{b}_{1}<\frac{\frac{s^{3} w^{3}}{2 c}\left(\bar{a}_{2}-a_{2}\right)+z\left(a_{1}-\bar{a}_{1}\right)+s^{2} w^{2} \bar{a}_{1}+2 s w c a_{2}}{4 c^{2}-2 s^{2} w^{2}}
\end{gathered}
$$

Hence, if agent 1 is overconfident and agent 2 is unbiased, then an increase in overconfidence of agent 1 increases the ex-post payoff of agent 1 if and only if overconfidence is not too extreme. 
If player 1 is underconfident $\left(\bar{b}_{1}<0\right)$ and player 2 is unbiased $\left(\bar{b}_{2}=0\right)$, then the impact of $\bar{b}_{1}$ on $\hat{U}_{1}$ is given by

$$
\begin{aligned}
\frac{\partial \hat{U}_{1}}{\partial \bar{b}_{1}} & =\frac{\partial \hat{U}_{1}}{\partial e_{1}} \frac{\partial e_{1}}{\partial \bar{b}_{1}}+\frac{\partial \hat{U}_{1}}{\partial e_{2}} \frac{\partial e_{2}}{\partial \bar{b}_{1}} \\
& =w\left(a_{1}+s e_{2}\right) \frac{\partial e_{1}}{\partial \bar{b}_{1}}-2 c e_{1} \frac{\partial e_{1}}{\partial \bar{b}_{1}}+w\left(a_{2}+s e_{1}\right) \frac{\partial e_{2}}{\partial \bar{b}_{1}} \\
& =\frac{-2 c w^{2}\left(a_{1}+s e_{2}\right)+4 c^{2} w e_{1}-s w^{3} a_{2}-s^{2} e_{1} w^{3}}{z} \\
& =-\frac{w\left[2 c w\left(a_{1}+s e_{2}\right)+s w^{2} a_{2}+z e_{1}\right]}{z}<0
\end{aligned}
$$

Hence, if agent 1 is underconfident and agent 2 is unbiased, then an increase in underconfidence of agent 1 reduces the ex-post payoff of agent 1. 


\section{Appendix C: Experimental Materials}

You are involved in an experiment organized by GATE laboratory. During this experiment, you will earn some money. Your monetary earnings depend on your decisions and other participants with which you will interact.

Timing of the experimental session

The experiment includes three parts.

In each part, you obtain a score for your decisions. Your score is measured in points. Your score in each part is revealed to you only at the end of the experiment. Your final earnings are equal to the sum of scores that you will obtain in the three parts. Your final earnings are measured in points. At the end of the experiment, they will be converted into Euros according to the following rate:

\section{5 points $=1$ Euro}

In addition, you will receive a 2 Euros show-up fee for participating in this experiment. Your final earnings will be paid to you in cash in a separate room before you leave the laboratory.

The instructions related to the first part are described below. The instructions for the next parts will be distributed later on.

\section{Timing of the first part}

The first part includes a preliminary task. We inform you that the score you will obtain in the preliminary task would, amongst other factors, determine how easy it will be for you to obtain some points later in the experiment. More precisely, the more points you obtain in the task, the easier it will be to obtain points in the third part of the experiment.

What is the preliminary task? 
The preliminary task consists in choosing two integers such as their sum is equal to the number to calculate. During the task, your screen is as follows:

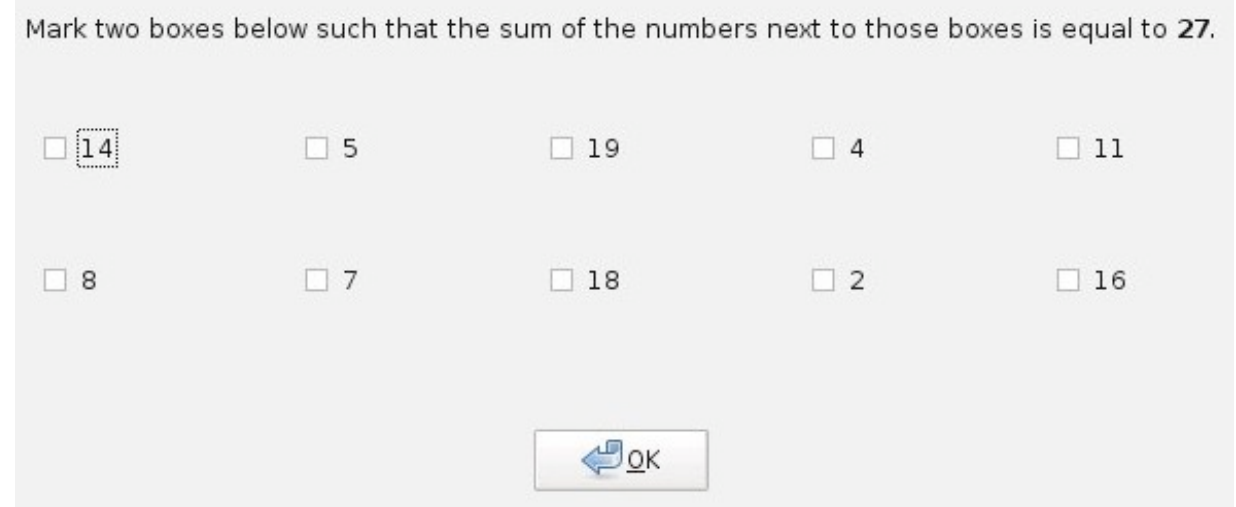

In this example, the number to calculate is 27 . The number to calculate is always shown on the top of your screen. To achieve the number to calculate you have to choose two integers among the ten shown, such as their sum is equal to the number to calculate. In the previous example, you can choose the integers 11 and 16 since their sum is equal to the number to calculate $(11+16=27)$. Several answers can be correct, but you have to choose only one.

You have $\mathbf{5}$ minutes to solve as many calculation problems as possible in a series. The calculation problems are randomly generated for five minutes. All the subjects are confronted with the same series of calculation problems. The calculation problems are shown one after another on your screen. You have to check off the two integers you choose and click on OK-button to validate your answer. You are not told whether your answer is correct or wrong. Every time that you click on OK-button, you go to the next calculation problem whatever your answer is.

What is your score in the first part?

Each correct answer gives you 2 points. The wrong answers do not lead to a loss of points. Thus your score in the preliminary task is equal to the number 
of correct answers you provide multiplied by 2. Your score in the task will be revealed to you only at the end of the experiment.

We remind you that your score in the task would, amongst other factors, determine how easy it will be for you to obtain some points later in the experiment.

Before performing the task, you are kindly requested to practice this task for one minute. During this practice period, the number of correct answers you provide is not taken into account for your score.

If you have any question regarding these instructions, please raise your hand.

Communication between participants is forbidden throughout the session.

\section{Timing of the second part}

The second part includes a self-evaluation question. At the beginning of part 2, the computer program compares the participants two by two and assigns them to a type (Type A or Type B). The types are assigned according to the number of correct answers provided by the two participants in the preliminary task of part 1 . Your decision consists in indicating the type that you think you are.

How are the types assigned?

The computer program compares the participants two by two. Each participant is compared with one and only one other participant. Then the computer program assigns a type to each of two participants according to the number of correct answers provided in the preliminary task. The participant who provided most correct answers is assigned to a Type A, while the one who provided least correct answers is assigned to a Type B. If both participants provided the same number of correct answers, the computer program decides between them according to the answer time. The fastest participant is assigned to a Type A, whereas the other to a Type B. 


\section{Your type is not reveal to you.}

The self-evaluation question:

Your decision consists in indicating the type that you think you are. You have to answer the following question:

Do you think to be a participant of Type A or Type B?

You have to enter your answer (A or B) and click on OK-button to validate it.

What is your score in the second part?

If your answer to the self-evaluation question is correct, your score for the second part is equal to $\mathbf{1 7 5}$ points (i.e. $\mathbf{5}$ Euros). Conversely, if your answer to the self-evaluation question is wrong, your score for the second part is equal to $\mathbf{0}$ point. Your score in the second part will be revealed to you only at the end of the experiment.

If you have any question regarding these instructions, please raise your hand.

\section{Timing of the third part (Treatment "Type and Belief")}

During the third part, you have to make $\mathbf{1 4}$ decisions. For each decision, the computer program randomly matches the participants into pairs. In each pair, you have to choose a number. In each pair, your score depends on the numbers that both you and your partner choose and on your type and your partner's (A or B).

Your coefficient:

At the beginning of the third part, the computer program gives you a coefficient. Your coefficient depends on your type. The participants of Type A have a high coefficient equal to 7 , whereas the participants of Type B have a low coefficient equal to 3 . Your coefficient does not 
change until the end of the experiment. Your coefficient will be revealed to you only at the end of the experiment.

\section{Your decisions:}

You have to make $\mathbf{1 4}$ decisions. For each decision, you are matched with one out of the 19 participants in the room. The pairs are changed for each decision such that you are never matched twice with the same participant. Consequently, you will play the game with 14 out of the 19 participants in the room. In each pair, your decision consists in choosing a number among the following four: $\mathbf{6 ,}, \mathbf{8}, \mathbf{1 0}$ or $\mathbf{1 2}$. You have to enter your 14 decisions in a single table and click on OK-button to validate them.

What is your score for each decision?

For each out of the 14 decisions, you get a score. Your score depends on the numbers chosen by you and your partner $(6,8,10$ et 12) and your coefficients (A or B). For each decision, the number that you choose has two effects:

- It negatively affects your score:

Your decision is costly. The cost that you bear depends on the number you choose.

- The higher the number you choose is, the higher the cost you bear is.

- It positively affects your score and your partner's:

The total payoff of the pair is equally divided between you and your partner. The total payoff of the pair depends on your coefficient and partner's one, and the numbers that you and your partner choose.

- The higher the numbers that you and your partner choose are, the higher the total payoff of the pair is.

- The higher your coefficient and partner's are, the higher the total payoff of the pair is.

For each decision, your score (in points) is thus calculated by the computer program as follows: 


$$
\begin{gathered}
\left.\frac{1}{2} * \text { [Total payoff of the pair }\right] \\
- \text { your cost }
\end{gathered}
$$

To make your 14 decisions, we give you the score tables. These tables show you your score and your partner's according to your coefficients (3 or 7 ) and the numbers you choose $(6,8,10$ or 12$)$. Be careful: these tables show you the scores, meaning that the cost you bear has already been deducted from the total payoff of the pair. These tables are presented on the two sheets of paper that we gave you with the instructions of part 3. One of the two sheets shows the score tables if you are assigned to a Type B and the other if you are assigned to a Type A. Each of these two sheets includes two tables. The first table shows you the scores if your partner is assigned to a Type B. The second table shows you the scores if your partner is assigned to a Type A.

How do you read these tables:

Assume that you are a participant of Type B and your partner also is a participant of Type B. Your coefficient and your partner's are equal to 3. Table 1 shows you your score and your partner's according to the numbers that you choose $(6,8,10$ or 12$)$. In each cell of the table, the score written at the bottom, on the left and in bold is yours, while the score written at the top on the right is the one of your partner. The scores are indicated in points.

- If you and your partner choose number 6, your score and your partner's are equal to 99 points.

- If you choose number 6 and your partner choose number 8 , your score is equal to 132 points and the one of your partner is equal to 90 points.

- If you choose number 10 and your partner choose number 8, your score is equal to 112 points and the one of your partner is equal to 166 points.

Available information when you are making your decisions: [The alternative instructions for treatment "Belief" are provided in brackets]

When you are making your 14 decisions, you do not know your type [Treatment "Belief": When you are making your 14 decisions, you know neither your type nor your partner's one]. During the second part of the experiment, each participant answered the self-evaluation question. Thus, each partici- 
pant indicated which type he thinks he is (A or B). When you are making your decisions, we remind you your self-evaluation. Moreover, for each of the 14 decisions we tell you the type and the self-evaluation of your partner [Treatment "Belief": Moreover, for each out of the 14 decisions we tell you the self-evaluation of your partner]. Consequently, you know the type of your partner, but not yours. Symmetrically, your partner knows your type, but not his. Since your partner does not know his type when he is making his decision, we tell you his self-evaluation. So you know which type your partner thinks he is [Treatment "Belief": those four last sentences are not in the instructions]. During the decision stage, you will see the following screen:

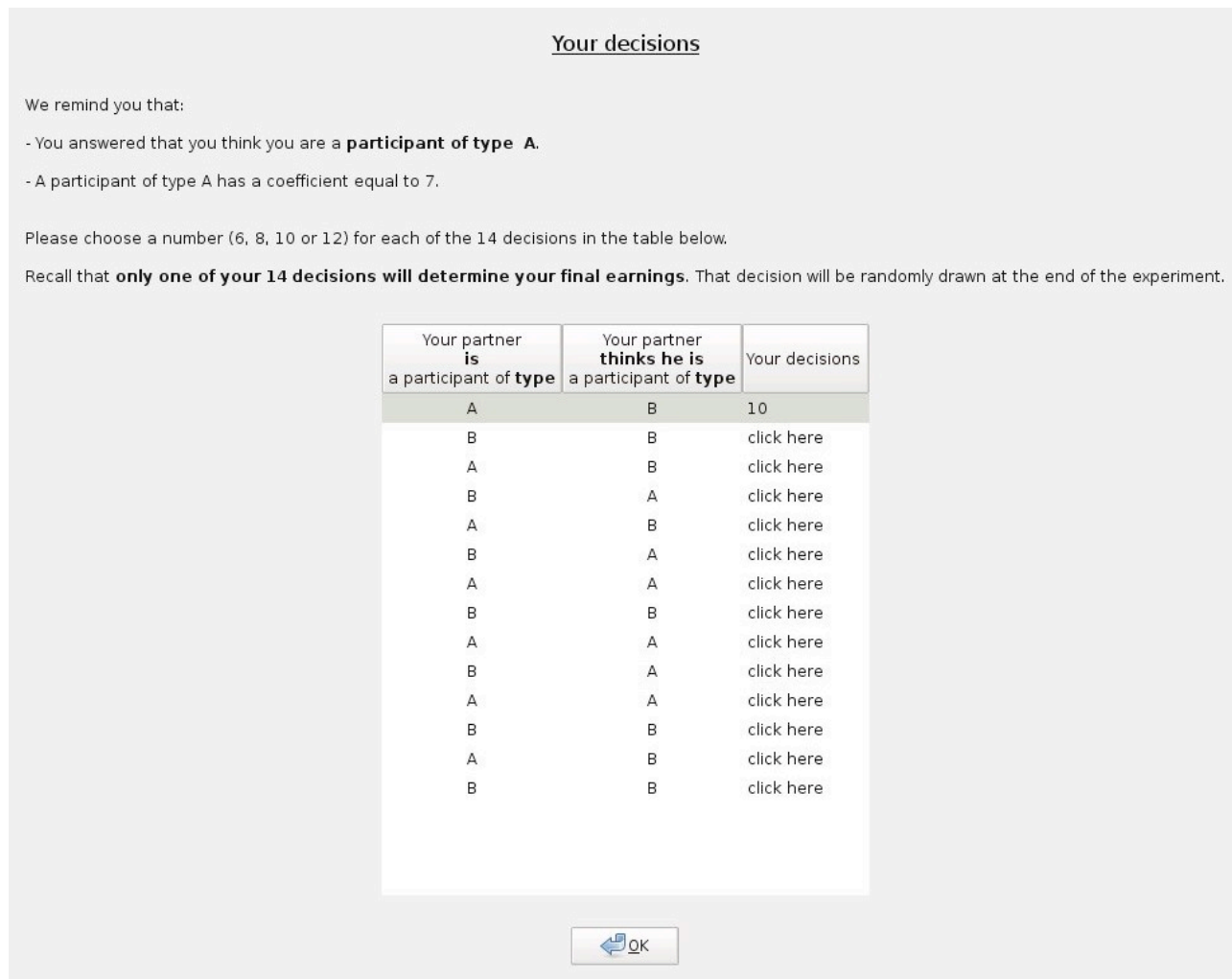

We remind you the type (A or B) that you think you are. This information is the same for the 14 decisions. On the other hand, the other informations can change from one decision to another since they concern your partners and the pairs are different for each decision. For each of the 14 decisions, the first column of table shows you the type of your partner [Treatment "Belief": this 
sentence is not in the instructions]. The second column [Treatment "Belief": the first column] shows you the self-evaluation of your partner. So, we tell you the type that your partner thinks he is. The 14 decisions are randomly ordered in the decision table. For each decision, you have to choose a number among 4 possible choices $(6,8,10$ or 12) and enter your decision in the third column [Treatment "Belief": in the second column]. After making your 14 decisions, you have to validate them by clicking on OK-button.

What is your score in the third part?

The third part includes 14 decisions. For each decision, you get a score. At the end of the experimental session, the computer program randomly draws one decision for each participant. The random draw is such that the same decision is drawn for you and your partner. Your score in part 3 is equal to the score you get for the randomly drawn decision.

In order to become familiar with the score tables, you have to complete some exercises that we are going to give you. If you have some difficulties for using the score tables, please raise your hand and we will come to help you.

At the end of the experiment, you have to complete a final questionnaire by following the instructions on your screen. This questionnaire allows you to get an additional gain that will be added to your final earnings.

If you have any question regarding these instructions, please raise your hand. 
You are a participant of "Type B"

Your coefficient is equal to 3

If your partner is a participant of "Type B".

His coefficient is equal to 3 and the payoff table is:

\begin{tabular}{|c|c|c|c|c|c|}
\hline & \multicolumn{4}{|c|}{ Your partner } \\
\hline & & 6 & 8 & 10 & 12 \\
\hline \multirow{4}{*}{ You } & 6 & $\begin{array}{ll}99 & 99\end{array}$ & $132 \quad 90$ & $\mathbf{1 6 5} \quad 69$ & 198 \\
\hline & 8 & 132 & $\mathbf{1 2 8}^{128}$ & $\mathbf{1 6 6} \mathbf{r}^{112}$ & $204 \quad 84$ \\
\hline & 10 & $69^{165}$ & $\mathbf{1 1 2}$ & 155 & 198 \\
\hline & 12 & $36^{198}$ & $\begin{array}{ll} & 204 \\
\mathbf{8 4} & \end{array}$ & $\mathbf{1 3 2}{ }^{198}$ & 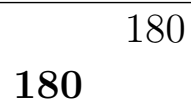 \\
\hline
\end{tabular}

Table 1

If your partner is a participant of "Type A".

His coefficient is equal to 7 and the payoff table is:

\begin{tabular}{|c|c|c|c|c|c|}
\hline & \multicolumn{4}{|c|}{ Your partner } \\
\hline & & 6 & 8 & 10 & 12 \\
\hline \multirow{4}{*}{ You } & 6 & $\mathbf{1 7 1}^{171}$ & $\mathbf{2 2 8}^{186}$ & $\begin{array}{ll} & 189 \\
\mathbf{2 8 5} & \end{array}$ & $\mathbf{3 4 2}^{180}$ \\
\hline & 8 & 162 & 224 & 286 & 348 \\
\hline & 10 & 237 & $\begin{array}{ll} & 262 \\
\mathbf{2 0 8} & \\
\end{array}$ & $\mathbf{2 7 5}{ }^{275}$ & 276 \\
\hline & 12 & $1088^{270}$ & $\begin{array}{ll} & 300 \\
180 & \end{array}$ & $\mathbf{2 5 2}^{318}$ & $\begin{array}{ll} & 324 \\
\mathbf{3 2 4} & \end{array}$ \\
\hline
\end{tabular}

Table 2 


\section{You are a participant of "Type A"}

Your coefficient is equal to 7

If your partner is a participant of "Type B".

His coefficient is equal to 3 and the payoff table is:

\begin{tabular}{|c|c|c|c|c|c|}
\hline & \multicolumn{4}{|c|}{ Your partner } \\
\hline & & 6 & 8 & 10 & 12 \\
\hline \multirow{5}{*}{ You } & 6 & 171 & 162 & 141 & 108 \\
\hline & 0 & 171 & 204 & 237 & 270 \\
\hline & 8 & $\mathbf{1 8 6} \mathbf{2}^{228}$ & $\mathbf{2 2 4}^{224}$ & $\mathbf{2 6 2}^{208}$ & $\mathbf{3 0 0}^{180}$ \\
\hline & 10 & 285 & 286 & 275 & 252 \\
\hline & 12 & $\mathbf{1 8 0}$ & $\begin{array}{ll} & 348 \\
\mathbf{2 2 8} & \end{array}$ & $\mathbf{2 7 6}$ & $\mathbf{3 2 4}^{324}$ \\
\hline
\end{tabular}

Table 3

If your partner is a participant of "Type A".

His coefficient is equal to $\mathbf{7}$ and the payoff table is:

\begin{tabular}{|c|c|c|c|c|c|}
\hline & \multicolumn{4}{|c|}{ Your partner } \\
\hline & & 6 & 8 & 10 & 12 \\
\hline \multirow{7}{*}{ You } & 6 & 243 & 258 & 261 & 252 \\
\hline & & 243 & 300 & 357 & 414 \\
\hline & 8 & 300 & 320 & 328 & 324 \\
\hline & & 258 & 320 & 382 & 444 \\
\hline & 10 & 357 & 382 & 395 & 396 \\
\hline & & 261 & 328 & 395 & 462 \\
\hline & 12 & $\mathbf{2 5 2}^{414}$ & $\mathbf{3 2 4}^{444}$ & $\begin{array}{ll} & 462 \\
396 & \end{array}$ & $4 \mathbf{4 6 8}^{468}$ \\
\hline
\end{tabular}

Table 4 